\title{
SCIENZA E RISCHIO FRA PREVEDIBILITÀ DELL'EVENTO E PREDITTIVITÀ DELLA DECISIONE GIUDIZIARIA
}

\author{
CIENCIA Y RIESGO ENTRE LA PREVISIBILIDAD DEL \\ EVENTO Y LA PREDICTIVIDAD DE LA DECISIÓN \\ JUDICIAL
}

\author{
SCIENCE AND RISK BETWEEN THE FORESEEABILITY \\ OF THE EVENT AND THE PREDICTABILITY OF THE \\ JUDICIAL DECISION
}

\author{
Cecilia VALBONESI*
}

Recibido: 30/04/2020

Aceptado: 30/06/2020

\begin{abstract}
SOMMARIO: I. Considerazioni introduttive; II. Scienza e prevedibilità dell'evento colposo negli incerti confini della modernità; II.1. Prevedibilità come preconizzabilità dell'evento colposo; II.2. Prevedibilità della decisone giudiziaria nella lente della creatività e del creazionismo; III. La risposta della giurisprudenza alla domanda di prevedibilità; III.1. I difficili rapporti fra scienza e prevedibilità dell'evento: dalla sentenza di "Porto Marghera" alla recente pronuncia sui fatti delle "Macalube di Aragona”; III.2. Le voci della speranza: la ricostruzione delle responsabilità per l'alluvione di Olbia alla luce di un agente modello in chiave assolutoria; IV. Dalla prevedibilità dell'evento ai doveri precauzionistici; V. Leggi scientifiche ed evitabilità dell'evento; VI. Periti e consulenti tecnici veri arbitri del processo; VI.1. La buona scienza nel processo: linee guida dalla giurisprudenza di legittimità; VI.2. Ma i problemi rimangono: affidabilità e imparzialità degli scienziati nel processo penale; VI.3. (segue) I problemi del rimprovero colposo (e qualche soluzione); VII. Il quesito rivolto al perito e al consulente tecnico in tema di reato colposo; VIII. Il futuro dei rapporti fra diritto e scienza: soluzioni possibili di una sinergia sempre più irrinunciabile.
\end{abstract}

RESUMEN: I. Consideraciones introductivas; II. II.1. La previsibilidad como preconcepción del hecho culpable; II.2. La previsibilidad de la decisión judicial desde el punto de vista de la creatividad y el creacionismo; III. La respuesta de la jurisprudencia a la cuestión de la previsibilidad; III.1. Las difíciles relaciones entre la ciencia y la previsibilidad del acontecimiento: de la sentencia "Porto Marghera" a la reciente sentencia sobre los hechos del "Macalube de Aragón"; III.2. Las voces de la esperanza: la reconstrucción de las responsabilidades de la inundación de Olbia a la luz de un agente modelo en términos absolutorio; IV. De la previsibilidad del acontecimiento a los deberes de precaución; V. Leyes científicas y posibilidad de evitar el evento; VI. Peritos y testigos periciales verdaderos árbitros del juicio; VI.1. La buena ciencia en el juicio: directrices de la jurisprudencia de la legitimidad; VI.2. Pero los problemas persisten: fiabilidad e imparcialidad de los científicos en el juicio penal; VI.3. (continuación) Los problemas del reproche culpable (y algunas soluciones); VII. La pregunta dirigida al experto y testigo pericial sobre el tema de los delitos culposos; VIII. El futuro de la relación entre el derecho y la ciencia: posibles soluciones de una sinergia cada vez más inalienable.

SUMMARY: I. Previous considerations; II. Science and predictability of the culpable event in the uncertain confines of modernity; II.1. Predictability as a preconception of the culpable event; II.2. Predictability of the judicial decision in the lens of creativity and creationism; III. The answer of jurisprudence to the question of predictability; III.1. The difficult relations between science and predictability of the event: from the "Porto Marghera" judgment to the recent ruling on the facts of the "Macalube of Aragon"; III.2. The voices of hope: the reconstruction of the responsibilities for the Olbia 
flood in the light of a model agent in absolute terms; IV. From the predictability of the event to precautionary duties; V. Scientific laws and voidability of the event; VI. Experts and technical advisors, true arbitrators of the trial; VI.1. Good science in the trial: guidelines from jurisprudence of legitimacy; VI.2. But the problems remain: reliability and impartiality of scientists in the criminal trial; VI.3. The problems of culpable reproach (and some solutions); VII. The question addressed to the expert and technical consultant on the subject of culpable crime; VIII. The future of the relationship between law and science: possible solutions of an increasingly inalienable synergy.

Abstract: Il lavoro vuole affrontare il rapporto fra prova scientifica, diritto e processo penale, sottolineando come in Italia la mancanza di cultura scientifica dei giudici e, parimenti, la carenza di regole riferite ai criteri di scelta dei periti e dei consulenti tecnici, porti spesso a decisioni giudiziarie molto lontane dal rispetto dell'ortodossia del rimprovero penale. Dopo aver illustrato alcuni casi giurisprudenziali, la riflessione si sofferma sulle possibili soluzioni di questa annosa questione, muovendo dalla disciplina introdotta dalla legge Gelli Bianco e dal DDL sul Testo Unico Amianto.

Parole chiave: Prova scientifica, colpa, giudice.

Resumen: El trabajo pretende abordar la relación entre la evidencia científica, el derecho y el juicio penal, destacando cómo en Italia la falta de cultura científica de los jueces y, del mismo modo, la falta de normas que se refieran a los criterios de selección de peritos y testigos periciales a menudo conduce a decisiones judiciales alejadas de la ortodoxia del reproche penal. Tras ilustrar algunos casos jurisprudenciales, la reflexión se centra en las posibles soluciones a esta cuestión de larga data, a partir de la disciplina introducida por la ley Gelli Bianco y el DDL sobre la Ley de amianto.

Palabras clave: Evidencia científica, culpabilidad, juez.

Abstract: The work aims to address the relationship between scientific evidence, law and criminal trial, stressing how in Italy the lack of scientific culture of judges and, likewise, the lack of rules referring to the criteria for the selection of experts and technical consultants, often leads to judicial decisions far from the orthodoxy of criminal reproach. After illustrating some jurisprudential cases, the reflection dwells on possible solutions to this long-standing question, starting from the discipline introduced by the Gelli Bianco law and the DDL on the Asbestos Act.

Key words: Scientific evidence, negligence, judge.

“No, la scienza non è un’illusione. Ma sarebbe illusione credere di poter trovare altrove quello che essa non può darci.”

S. FREUD, L'avvenire di un'illusione, 1927 


\section{CONSIDERAZIONI INTRODUTTIVE}

Nessun ambito del rimprovero penale ha subito una simile destrutturazione, scientemente attuata per soddisfare le esigenze di repressione di condotte dotate di altissimo impatto tanto sulle vittime, quanto sull'opinione pubblica ${ }^{1}$.

La volontà di affidare al rimprovero colposo il ruolo di strumento di giustizia sociale ha sterilizzato il precetto dell'art. 27 Cost., ormai non più idoneo ad esercitare la sua funzione di baluardo contro quella responsabilità da posizione oggi così popolare negli ambiti più sensibili della sicurezza sul lavoro, delle malattie professionali e dei disastri naturali ${ }^{2}$.

La perdita di centralità della quale soffre il principio di colpevolezza presenta una etiologia multifattoriale. Fra i numerosi elementi determinanti ve ne sono però, a ben vedere, alcuni di maggiore incidenza e centralità sui quali può essere utile riflettere

\footnotetext{
${ }^{1}$ Lo ricorda PIERGALLINI, C. (2006), Esposizione ad amianto e tutela della salute: profili penalistici, in MONTUSCHI, L. - INSOLERA, G. (a cura di), Il rischio da amianto, Bologna, p. 31; ID, (1997), Attività produttive e imputazione per colpa: prove tecniche di «diritto penale del rischio» in Riv. it. dir. proc. pen., p. 1473. Nello stesso senso FORNARI, L. (1999), Descrizione dell'evento e prevedibilità del decorso causale: «passi avanti» della giurisprudenza sul terreno dell'imputazione col- posa, in Riv. it. dir. proc. pen., p. 725. In merito, fondamentale importanza rivestono anche i testi di BECK, U. (2000), La società del rischio. Verso una seconda modernità, Roma, passim. Si veda inoltre STELLA, F. (2003), Giustizia e modernità. La protezione dell'innocente e la tutela delle vittime, Milano, p. 156; CENTONZE, A. (2004), La normalità dei disastri tecnologici. Il problema del congedo dal diritto penale, Milano, p. 178; GARGANI, A. (2011), Dal diritto penale dell'evento al diritto penale del rischio: problemi e prospettive, relazione al convegno del CSM Il diritto penale del rischio, Roma 2-4 maggio 2011, p. 2; PERINI C. (2011), Il concetto di rischio nel diritto penale moderno, Milano, p. 519. Per una visione d'insieme sul rischio consentito nell'imputazione colposa $v$. MILITELLO, V. (1988), Rischi e responsabilità penale, Milano, p. 152; l'ingresso di una "responsabilità per rischio" nel diritto penale, soprattutto con riferimento al crimen culposum, sembra superare quella dicotomia fra diritto civile e diritto penale che autorevole dottrina aveva individuato proprio sul concetto di rischio. Si osserva che "il progressivo allontanamento della responsabilità civile dal terreno della colpa verso i confini del rischio determina parallelamente l'abbandono, da parte del risarcimento del danno, di ogni funzione retributiva a vantaggio della funzione base riparatoria o reintegrativa. Nulla di eccezionale in tutto ciò, posto che, a differenza di quanto avviene per il reato, la Costituzione non cristallizza una determinata funzione della responsabilità civile. Rimane tutt'al più aperto il quesito se nelle ipotesi di responsabilità per rischio possano coesistere con il (o sostituirsi al) risarcimento del danno forme di sanzioni strutturalmente coincidenti con sanzioni penali (accessorie) ... La risposta più coerente dovrebbe essere quella negativa, ad evitare che tramite il pretesto della responsabilità per «rischio» si realizzi una «truffa delle etichette»”. Così BRICOLA, F., Teoria generale del reato, in Nov.mo dig. it., vol. XIX, Torino, 1973, p. 7 oggi in ID. (1997), Scritti di diritto penale, Vol I. Dottrine generali. Teoria del reato e sistema sanzionatorio. Tomo 1. Dal 1960 al 1963, a cura di CANESTRARI, S.-MELCHIONDA, A. (a cura di), Milano, p. 675-68; MASSARO, A. (2009), «Concretizzazione del rischio» e prevedibilità dell'evento nella prospettiva della doppia funzione della colpa, in Cass. pen., p. 4699; PERINI, C. (2011), Dal diritto penale dell'evento al diritto penale del rischio: problemi e prospettive, Parte II, relazione al convegno del CSM Il diritto penale del rischio, Roma 2-4 maggio 2011, p. 1; GROTTO, M. (2015), Obbligo di informazione e formazione dei lavoratori, nesso di rischio e causalità della colpa, in www.penalecontemporaneo.it, 16 settembre 2015 [consultato il 13 giugno 2019].

${ }^{2}$ DI SALVO, E. (2009), Esposizione a sostanze nocive, leggi scientifiche e rapporto causale nella pronuncia della Cassazione sul caso Porto Marghera (nota a Cass. sez. IV, 6 febbraio 2007, 4675, imp. Bartalini), in Cass. pen., p. 2877. Nello stesso senso, MICHELETTI, D. (1996), Tumori da amianto e responsabilità penale, in Riv. trim. dir. pen. econ., p. 231; SGUBBI, F. (2001), Il diritto penale incerto ed efficace, in Riv. it. dir. pen. econ., p. 1197; STORTONI, L. (2004), Angoscia tecnologica ed esorcismo penale, in Riv. it. dir. proc. pen., p. 70; PIERGALLINI, C. (2005), Paradigma della colpa nell'età del rischio: prove di resistenza del tipo, in Riv. it. dir. pen. econ., p. 1697; PULITANÒ, D. (2008), Colpa ed evoluzione del sapere scientifico, in Dir. pen. proc., p. 649;
} 
non solo in chiave stigmatizzante, ma altresì in prospettiva di recupero di una legalità della colpa che da tempo manca nelle aule giudiziarie.

La Dottrina appare invero divisa sui profili del rimprovero colposo attraverso i quali è possibile veicolare un intervento volto al recupero dell'ortodossia e dell'ossequio ai principi costituzionali.

Autorevoli interpreti hanno sottolineato come il futuro della riflessione debba incentrarsi sulla misura soggettiva della colpa ${ }^{3}$.

Altri, in modo che appare maggiormente efficace e pregnante, suggeriscono di recuperare il rimprovero colposo ad una rinnovata tipicità che, in ossequio alla natura normativa della colpa, rafforzi la determinazione e determinatezza di un precetto cautelare disponibile ex ante, tanto per l'operatore del rischio, quanto per il giudice. ${ }^{4}$

La costruzione di un terreno cautelare condiviso, sottratto ai seducenti parametri dell'agente modello e della regola astensionistica, restituisce alla colpa il suo paradigma positivo, finalmente privo di quelle declinazioni del dover essere che, in modo del tutto opportunistico, possono piegarne i contorni.

Con questo, certo, non si è inteso esaurire il precetto colposo alla sola dimensione della colpa specifica, poiché appare chiaro come la colpa generica costituisca elemento di determinazione maggiormente puntuale dei doveri di diligenza da attuare nel caso concreto. Piuttosto, si è sottolineata la necessità di privare il giudice della facoltà di individuazione di una regola cautelare creata ad hoc ed ex post, sulla base delle esigenze sanzionatorie del caso concreto.

La giurisprudenza di merito e di legittimità da ormai un ventennio ci consegna, infatti, soluzioni colpevoliste costruite sulla base di saperi del senno di poi, che frustrano, in modo irreparabile, le istanze di giustizia costituzionalmente presidiate.

L'analisi di questa giurisprudenza, che sarà condotta in modo certamente non esaustivo nell'articolazione del presente lavoro, ci consegna il compito di avviare una riflessione ulteriore e complementare sui profili costitutivi della regola cautelare, la quale prende vita - come noto - dalla previa determinazione dello spettro di prevedibilità ed evitabilità dell'evento.

Non a caso, infatti, come avremo modo di dimostrare, prevedibilità ed evitabilità dell'evento rappresentano il fulcro della distorsione operata dal giudice ed attuata, in modo pressoché indefettibile, attraverso un utilizzo improprio, scorretto o strumentale dei saperi scientifici che entrano nel processo.

Il ruolo della scienza nel processo penale è, dunque, oggi più che mai fondamentale ${ }^{5}$.

Dalla sua solidità e correttezza dipende l'esatta individuazione dello spettro cautelare la cui inosservanza può essere colpevolmente ascritta all'agente ${ }^{6}$.

\footnotetext{
${ }^{3}$ GROTTO, M. (2012), Principio di colpevolezza, rimproverabilità soggettiva e colpa specifica, Torino, passim. In modo conforme CASTRONUOVO, D. (2009), La colpa penale, Milano, p. 182.

${ }^{4}$ GIUNTA, F. (1993), Illiceità e colpevolezza nella responsabilità colposa, Padova, pp. 14, 133, 141, 150, 155; MICHELETTI, D. (2008), La colpa del medico, Prima lettura di una recente ricerca sul campo, in Criminalia, p. 174.

${ }^{5}$ Sulle accezioni di "prova scientifica", GIUNTA, F. (2015), Questioni scientifiche e prova scientifica tra categorie sostanziali e regole di giudizio, in BERTOLINO, M. - UBERTIS, G. (a cura di), Prova scientifica, ragionamento probatorio e decisione giudiziale, Napoli, p. 57.

${ }^{6}$ Sul tema ex multis CONTI, C. (2009), Evoluzione della scienza e ruolo degli esperti nel processo penale, in S. CANESTRARI, S.- GIUNTA, F. - GUERRINI, R. - PADOVANI, T. (a cura di), Medicina e diritto penale, Pisa, p. 336; ancora, sul tema del rapporto fra conoscenze scientifiche e libero convincimento del giudice, DOMINIONI, O. (2012), In tema di nuova prova scientifica, in Dir. pen.
} 
Infatti, alla regola scientifica è conferito il compito di rivelare al giudice e alla collettività lo spettro di eventi che l'agente concreto poteva prevedere e gli strumenti dei quali egli poteva disporre per scongiurarlo e mitigarne le conseguenze.

A ben vedere, questo assunto ci mostra in tutta la sua interezza la fragilità del rimprovero colposo, affidato a parametri epistemologici sovente di natura incerta, contraddittoria o in continuo divenire. La scienza, per sua natura, è dubbio ${ }^{7}$.

Ma se fisiologica appare la plurivocità e l’incertezza che caratterizza il dibattito scientifico, patologica è invece spesso la modalità attraverso la quale questi saperi fanno ingresso nel processo penale. È noto, infatti, come la funzionalizzazione della scienza all'accertamento della verità processuale sia riservata alla figura dei periti e consulenti tecnici i quali offrono al giudice, al pubblico ministero e alle altre parti la spiegazione delle correlazioni fra condotta ed evento in senso giuridico o naturalistico.

Proprio su questa necessaria sinergia fra scienza, tecnica e diritto si innestano le matrici di uno dei più grandi drammi che affliggono la giustizia italiana ${ }^{8}$. Ci riferiamo alla scorretta, obsoleta o inesistente risposta scientifica che spesso viene offerta ai fatti oggetto della cognizione giurisdizionale, la quale finisce per affiancare alle vittime del reato, le vittime del processo, destinatari di una condanna ingiusta.

Solo in rari casi tanto la Suprema Corte, quanto i giudici di merito, si rivelano preparati a contrastare le seduzioni della cattiva scienza, della ricostruzione non fondata su parametri empiricamente verificabili e riproducibili, frutto della miglior scienza ed esperienza del momento storico ${ }^{9}$.

Le vittime processuali della regola scientifica costruita ad hoc da un giudice convinto, oltre ogni ragionevole dubbio, della loro colpevolezza scontano la mancanza di un quadro normativo adeguato, sia dal punto di vista prescrittivo che sanzionatorio, e della ancor più grave carenza etica che talvolta caratterizza l'esercizio della funzione giurisdizionale.

Nell'attesa che il legislatore e gli Organismi rappresentativi delle figure professionali coinvolte adottino interventi normativi e regolamentari idonei a dare risposta alle ormai non più procrastinabili esigenze di giustizia che un ordinamento

proc., p. 1064; TONINI, P. (2003), Prova scientifica e contraddittorio, in Riv. it. dir. proc. pen., p. 1459 ss.; DOMINIONI, O. (2005), La prova penale scientifica. Gli strumenti scientifico-tecnici nuovi o controversi e di elevata specializzazione, Milano, passim; TARUFFO, M. (2005), Conoscenza scientifica e decisone giudiziaria: profili generali, in AA. VV., Decisione giudiziaria a verità scientifica, Milano, p. 6.

${ }^{7}$ La Dottrina sottolinea come "oggi sappiamo che la scienza non è completa, perché non appena altri aspetti del medesimo fenomeno sono conosciuti, la legge scientifica deve essere ampliata o modificata per considerare anche tali profili”. Così TONINI, P. (2011), Dalla perizia "prova neutra" al contraddittorio sulla scienza, in CONTI, C., (a cura di), Scienza e processo penale. Nuove frontiere $e$ vecchi pregiudizi, Milano, p.6.

8 Sui rapporti fra scienza e diritto, STELLA, F. (2002), Giustizia e modernità, La protezione dell'innocente e la tutela delle vittime, cit., passim. Ed ancora, ID, (1999), Scienza e norma della pratica dell'igiene industriale, in Riv. it. dir. proc. pen. p. 382; ID, (2003), La costruzione giuridica della scienza: sicurezza e salute negli ambienti di lavoro, in Riv. it. dir. proc. pen., p. 55; Nella dottrina processualistica, ex plurimis, TONINI, P. (2008), La prova scientifica: considerazioni introduttive, in Dir. pen. proc., n.6, Dossier La prova scientifica nel processo penale, p. 7 ss.; nella giurisprudenza, BLAIOTTA, R. (1997), Il realismo di Karl Popper: un ideale di conoscenza oggettiva per il giudizio penale, in Cass. pen., p. 3689. Si veda inoltre ACCINNI, G. P. (2006), Criteri di imputazione per colpa tra leggi scientifiche e accertamenti giudiziali, in Riv. it. dir. proc. pen., p. 930.

${ }^{9}$ Ex plurimis, DI SALVO, E. (2009), Esposizione a sostanze nocive, leggi scientifiche e rapporto causale nella pronuncia della Cassazione sul caso 'Porto Marghera' [Nota a sentenza] sez. IV, 17 maggio 2006, n. 4675, imp. Bartalini, cit., p. 2788. 
democratico impone, è possibile qui ricostruire i profili di maggiore problematicità sui quali si riverbera questa grave carenza di metodo scientifico che affetta il processo ${ }^{10}$.

Per questo motivo, l'indagine, muovendo dalla determinazione del ruolo conferito al sapere epistemologico dalla stessa giurisprudenza, si concentrerà su: 1. I rapporti fra scienza, prevedibilità dell'evento e prevedibilità della decisone giurisdizionale nei maggiori contesti di rischio; 2. Sulle torsioni che l'incertezza scientifica imprime alla prevedibilità e all'evitabilità dell'evento colposo, dando così sempre più spazio agli afflati precauzionistici di matrice europeista; 3. Sul ruolo centrale dei periti e dei consulenti tecnici, ai quali è affidata la determinazione del coefficiente scientifico del rimprovero colposo; 4. Sulle storture correlate a questa funzione ed imputabili all'insufficienza delle regole sostanziali e processuali atte a regolarla.

L'analisi, condotta alla luce di alcune significative pronunce di merito e di legittimità, si concluderà con il tentativo di delineare alcune soluzioni volte al recupero del ruolo della buona scienza nel processo.

\section{SCIENZA E PREVEDIBILITÀ DELL'EVENTO COLPOSO NEGLI INCERTI CONFINI DELLA MODERNITÀ}

Nonostante la giurisprudenza di legittimità più illuminata abbia offerto puntuali, ancorché non esaustive, linee guida volte ad assicurare una decisione giurisdizionale fondata sulla "buona scienza" è dura a morire quella comune prassi giudiziaria che vede l'utilizzo di leggi espistemologiche fallaci, spesso veicolate da consulenti tecnici e periti non adeguati al tenore del quesito proposto. ${ }^{11}$

La frattura fra scienza e rimprovero colposo, che si consuma sul terreno della tipicità, sembra evocare gli assunti della famosa conferenza di Cambridge del 1959 nella quale Charles Percy Snow tracciò i confini della irrisolvibile dicotomia tra cultura umanistica e cultura scientifica. Ammesso e non concesso che il diritto appartenga a una delle due categorie, quel che appare evidente è la mancanza di un comune terreno culturale, semantico, concettuale nel quale possa consumarsi il necessario incontro fra regole di condotta e regole scientifiche ${ }^{12}$.

\footnotetext{
${ }^{10}$ Peraltro, il rapporto fra scienza e processo acuisce le sue criticità nel momento in cui ci domandiamo se "il sapere scientifico entra .... anche nel processo, al fine provare fatti, oppure nel diritto penale sostanziale al fine di imputare i fatti” BARTOLI, R. (2018), Diritto penale e prova scientifica, in CANZIO, G.-LUPARIA, L. (a cura di), Prova scientifica e processo penale, Milano, p. 80. Infatti, "se l'interazione fra conoscenze scientifiche e valutazione giudiziale è sempre più spesso imposta dalle difficoltà di prova che insorgono nei processi ad alta complessità fattuale, è anche vero che in alcuni casi l'approccio interdisciplinare si rende necessario ancor prima di procedere all'accertamento processuale. Sono questi i casi in cui il contributo dei saperi scientifici risulta già utile per ricostruire i presupposti della responsabilità sul versante dello stesso diritto penale sostanziale: per cui la necessità di fare ricorso ad esperti portatori di conoscenze specialistiche, lungi dal derivare da esigenze puramente probatorie, costituisce il riflesso della complessità scientifica che caratterizza - più a monte - le categorie sostanziali che vengono in rilievo", FIANDACA, G. (2005), Il giudice di fronte alle controversie tecnico scientifiche. Il diritto e il processo penale, in Diritto e questioni pubbliche, p. 9.

11 Queste linee guida destinate a consentire l'ingresso della buona scienza nel processo penale sono rinvenibili in Cass. pen. sez. IV, 23 dicembre 2010, n. 43786, imp. Cozzini, cit. con commento di ZIRULIA, S., Amianto e responsabilità penale: causalità ed evitabilità dell'evento in relazione alle morti derivate da mesotelioma pleurico, in www.penalecontemporaneo.it.

12 Di particolare interesse SNOW, C. P. (2005), Le due culture, Marsilio, 2005, 137 traduzione di SNOW, C. P. (1959), The Two Cultures and a Second Look, Cambridge University Press.
} 
Non bisogna, infatti, dimenticare che la rinuncia da parte dell'autorità giudiziaria a fondare il rimprovero penale su parametri scientifici, scelta deprecabile che noi stigmatizziamo per lo più nella sua fenomenologia processuale (e procedimentale), affonda talvolta le sue origini nell'impossibilità stessa di determinare ex ante i contorni di una regola di condotta univoca, frutto della miglior scienza ed esperienza nel momento storico.

Per il giurista, abituato ad applicare schemi concettuali che si muovono nell'alternativa dicotomica tipicità-atipicità, è molto difficile cogliere le contraddizioni che animano alcuni settori del dibattito scientifico dove il pluralismo appare come un valore.

Pur tuttavia, questa immensa complessità non può essere posta a motivo che giustifica prassi sciatte o pericolosamente contrarie ai canoni di costituzionalità del rimprovero penale ${ }^{13}$.

Anzi, proprio il diritto dovrebbe farsi interprete della dimensione unitaria della cultura, nella quale la valenza giuridica di casi caratterizzati da peculiari connotazioni scientifiche sia posta all'attenzione del giudice chiamato a realizzare una visione sincretica, spesso, però, di difficile realizzabilità.

A dispetto di questo anelito, non pare tuttavia revocabile in dubbio come l'“alleanza” che si consuma fra rimprovero penale colposo e scienza appaia oltremodo "incerta” e sia, per questo, foriera di un costo sociale incalcolabile ${ }^{14}$.

L'assunto trova la sua dimostrazione più compiuta e drammatica sul duplice e sovente complementare terreno della: 1. prevedibilità dell'evento "con cui si individuano le condotte pericolose, essendo tali le condotte tenendo le quali è prevedibile come probabile la verificazione di eventi lesivi”" ${ }^{15}$; 2 . prevedibilità della decisione giudiziaria quale parametro di legalità di matrice sovranazionale.

\footnotetext{
${ }^{13}$ Tanto più che come ricorda la Dottrina, disponiamo da tempo di modelli idonei ad accertare in modo corretto la verità processuale. Infatti, si sottolinea come sia "in atto uno scontro fortissimo fra due differenti concezioni del processo penale e soprattutto della prova. Lo scontro è in corso dal 2002 e cioè a partire dalla sentenza delle Sezioni Unite Franzese, che sulla prova scientifica ha enunciato novità dirompenti rispetto alla giurisprudenza tradizionale. In passato si riteneva che il compito dello scienziato fosse quello di affermare in modo definitivo le conclusioni da trarre dalla circostanza indiziante. Ed il giudice non essendo esperto non poteva valutare se la legge scientifica fosse valida e se fosse stata correttamente applicata nel caso concreto. Prima della sentenza Franzese, quindi, si pensava che l'errore scientifico non fosse emendabile ne processo. Grazie alla sentenza Franzese del 2002, viceversa, si è affermato che il giudice deve controllare l'esperto, deve accertare se la legge scientifica è valida in generale e fare un tentativo di smentita e, infine, deve controllare se quella legge scientifica in concreto ha operato per valutare se quell'effetto eventualmente possa derivare anche da una differente causa. Dal 2002 in poi non basta più che un esperto della polizia, del pubblico ministero, della difesa o lo stesso perito, impegni la sua parola dicendo quali sono le cause dei fatti accertati. Occorre che ad un altro esperto sia permesso di tentare di smentire quella ricostruzione. Solo così il ragionamento può essere definito "scientifico". Nel processo del nuovo millennio la scienza non è Vangelo, può e deve essere messa in dubbio e sottoposta a controlli serrati”. Così, TONINI, P. (2015), Nullum iudicium sine scientia. Cadono vecchi idoli nel caso Meredith Kercher, in Dir. pen. proc., p. 1411.

${ }^{14}$ LIPARI, N. (2015), Il diritto quale crocevia fra le culture, in Riv. trim. dir. proc. civ., 2015, p. 1 il quale richiama GALLINO, L. (2012), L'incerta alleanza: modelli di relazione fra scienze umane $e$ scienze della natura, Torino, passim.

${ }^{15}$ Così MANTOVANI, F. (2017), Diritto penale. Parte generale., Padova, p. 333. Sulla prevedibilità dell'evento nella letteratura penalistica, ex plurimis, GIUNTA, F. (1999), La normatività della colpa penale. Lineamenti di una teorica, in Riv. it. dir. proc. pen., p. 95. Si veda inoltre, BRUSCO, C. (2010), Brevi considerazioni sulla prevedibilità dell'evento nel reato colposo, in BARTOLI, R. (a cura di), Responsabilità penale e rischio nelle attività mediche e d'impresa, Firenze, p. 493; VERRICO, A. (2011), La prevedibilità e l'evitabilità dell'evento nel caso di calamità naturali, in Cass. pen., p. 110;
} 
Infatti, la rinuncia al metodo scientifico, inficiando irrimediabilmente la possibilità stessa di determinare ex ante la regola di condotta, apre la porta all'assoluta discrezionalità del giudice il quale, di volta in volta, e sulla base del senno di poi deciderà liberamente della sussistenza o meno del rimprovero colposo. Con buona pace dei diritti fondamentali del cittadino, il quale non può in alcun modo prevedere le conseguenze dell'applicazione giurisprudenziale dell'inosservanza del dovere di diligenza che integra il precetto colposo ${ }^{16}$.

Una imprevedibilità mediata, dunque, che finisce tuttavia per spiegare conseguenze di tenore drammatico se solo pensiamo all'importanza che la regola di diligenza del precetto colposo riveste, sub specie di regola di condotta, ancor prima che regola di giudizio, nella nostra società del rischio nella quale "la curva della criminalità colposa segna ... dappertutto un aumento spaventoso, impressionante” ${ }^{17}$.

\section{Prevedibilità come preconizzabilità dell'evento colposo}

Per offrire una più compiuta dimostrazione di come l'oscurantismo di quest'epoca stia contagiando tutti gli aspetti della prevedibilità, è opportuno muovere, in primo luogo, dall' importanza che la giurisprudenza da tempo riserva alla preconizzabilità dell'evento.

Come ricorda la dottrina, "la prevedibilità ha svolto una duplice funzione, rilevando, da un lato, come criterio diagnostico della situazione di pericolo, dall'altro come base valutativo esperienziale e scientifica per la formazione della regola di comportamento doverosa, espressiva della c.d. evitabilità" ${ }^{18}$. Se nel contesto della colpa generica la prevedibilità dell'evento assume una funzione genetica della regola di condotta che si vorrebbe ricostruire, ponendosi in una prospettiva ex ante, nella colpa

BRUSCO, C. (2012), Rischio e pericolo, rischio consentito e principio di precauzione. La c.d. "flessibilizzazione delle categorie del reato», in Criminalia, p. 383. Di fondamentale importanza non solo PIERGALLINI, C. (2005), Il paradigma della colpa nell'età del rischio: prove di resistenza del tipo, in Riv. it. dir. proc. pen., p. 1692 e PULITANÒ, D. (2006), Gestione del rischio da esposizioni professionali, in Cass. pen., p. 778, ma altresì MICHELETTI, D. (2009), La normatività della colpa medica nella giurisprudenza della Cassazione, in Medicina e diritto penale, in CANESTRARI, S.GIUNTA, F.- GUERRINI, R. - PADOVANI, T. (a cura di), Pisa, p. 266. Fondamentali altresì GIUNTA, F. (1999), I tormentati rapporti fra colpa e regola cautelare, in Dir. pen. proc., 1295; MICHELETTI, D. (2000), La colpa nella bancarotta semplice patrimoniale, in Riv. tim. dir. pen. econ., p. 628; GIUNTA, F., (2002) Principio e dogmatica della colpevolezza nel diritto penale d'oggi, in Riv. it. dir. proc. pen., p. 123.

${ }^{16}$ Ex plurimis, VIGANÒ, F. (2016), Il principio di prevedibilità della decisione giudiziale in materia penale, in PALIERO, C.E. - MOCCIA, S.- DE FRANCESCO, G. A. - INSOLERA, G. - PELISSERO, M.- RAMPIONI, R.- RISICATO, L. (a cura di), La crisi della legalità. Il "sistema vivente delle fonti penali”, ESI, Napoli. Il contributo costituisce la relazione - ampliata, aggiornata e corredata di note presentata al convegno annuale dell'Associazione dei Professori di diritto penale svoltosi presso l’Università Federico II di Napoli il 7 e 8 novembre 2014.

17 MARINUCCI, G. (2012), Il ruolo delle regole scritte di diligenza nell'era dello sviluppo tecnico, Relazione presentata al Convegno "La criminalità colposa: aspetti giuridici e medico sociali" Camerino, 24-24 ottobre 1971, pubblicata nella sua originaria versione, in I quaderni degli incontri, 114, 1972, p. 5 e 79 e oggi pubblicata nel volume La Colpa, Studi, Milano, p. 295. L'Autore precisa poi che "il crescente dilagare dei fatti colposi non sta a significare uno scadimento delle attitudini medie individuali, ma, più semplicemente, è da porsi in relazione - per unanime riconoscimento degli studiosi delle più diverse discipline - con l'avvento del macchinismo in genere e della motorizzazione di massa in specie”.

${ }^{18}$ GIUNTA, F. (2016), Maxima culpa, in Giust. Pen., p. 635. 
specifica invece la prevedibilità “opera come presupposto della regola cautelare, ossia della sua adozione" 19 .

Le speranze riposte nella progressiva codificazione delle cautele, quale strumento volto a rafforzare la tipicità del rimprovero colposo e correlativamente ridurre la discrezionalità del giudice, chiamato a individuare ex post il dovere di diligenza violato, appaiono tuttavia naufragare miseramente in ragione della forzatura che lo stesso canone di prevedibilità si trova a subire ${ }^{20}$.

Questo, privato del suo sostrato scientifico ed ancorato spesso al fallace parametro ridescrittivo affidato a presunte massime di esperienza, perde la sua identità sistematica e confluisce talvolta nell'arbitrio.

Superati talvolta anche i limiti del fortuito ${ }^{21}$, si assiste a "problematiche forme di dilatazione del requisito della prevedibilità" che concernono "da un lato, il suo oggetto, dall'altro i suoi parametri di modulazione, per l'esattezza la base giustificativa e il grado di verosimiglianza"22.

Il progressivo depauperamento della base scientifica che sorregge il sostrato nomologico e financo esperienziale della colpa ha dato luogo all'ingresso di temibili parametri di giudizio affidati, come vedremo anche in seguito, allo spettro del precauzionismo.

Quest'ultimo si sostanzia nell'imposizione di doveri squisitamente astensionistici: dinanzi alle incertezze del rischio, il soggetto destinatario della regola cautelare è chiamato ad astenersi dal compiere la condotta i cui riflessi risultino anche solo potenzialmente dannosi. La circostanza appare chiara nella nota vicenda del Petrolchimico di Porto Marghera nel contesto della quale i giudici hanno ritenuto che il necessario ossequio alla default option avrebbe imposto al datore di lavoro di comportarsi come se il CVM fosse cancerogeno (sic!), astenendosi di conseguenza dal compiere quel tipo di lavorazione ${ }^{23}$.

Parimenti, quando di un fenomeno naturale non si conoscano le potenziali conseguenze perché non sono disponibili precedenti che consentano di determinare, nello specifico, il rango della cautela maggiormente idonea a scongiurare l'evento, la sola conoscibilità del pericolo impone scelte utraprudenziali totalmente sganciate da un modello di prevedibilità ossequioso di canoni scientifico - esperienziali.

A identiche conclusioni perviene la Suprema Corte chiamata a giudicare la responsabilità del sindaco e di un assessore per il delitto di omicidio colposo plurimo dei 137 cittadini, che nel Maggio 1998, a Sarno, furono investiti da devastanti colate di fango, provocate da intense precipitazioni piovose.

Nonostante la portata di queste ultime avesse assunto, nel caso di specie, una connotazione insolitamente imponente, la Corte ritiene che un simile fenomeno idrogeologico costituisca fattore ricorrente. A Sarno infatti, nel corso del ventesimo secolo, si erano verificati già altri quattro episodi di simile (ma non così devastante) intensità.

\footnotetext{
${ }^{19}$ F. GIUNTA, p. 635.

${ }^{20}$ Questo ovviamente non significa, come vedremo, che si possa rinunciare ad un progressivo processo di codificazione delle cautele.

${ }^{21}$ Di assoluto interesse, in proposito, le ultime riflessioni di MARINUCCI, G., Brevi note sul caso fortuito come scusante del fatto colposo, Nota a Trib. Firenze, Sez. I, 18.6.2012 (dep. 15.11.2012), Giud. Boncompagni, in www.penalecontempornaeo.it, 13 maggio 2013 [consultato il 13 giugno 2019].

22 GIUNTA, F. p. 636.

${ }^{23}$ Così il leading case di Cass. pen. sez. IV, 17 maggio, 2006, n. 4675, in DeJure.
} 
Il sindaco del Comune era accusato - titolo di colpa generica e specifica - di aver violato numerose norme di Protezione civile ed in particolare di aver omesso di: 1. dare tempestivamente l'allarme alla popolazione; 2 . disporne l'immediata evacuazione; 3. convocare e insediare tempestivamente il comitato locale per la Protezione civile; 4. dare tempestivo allarme alla Prefettura. Altresì all'assessore, in concorso con il sindaco, era contestata la diffusione presso la popolazione di notizie falsamente rassicuranti ${ }^{1}$.

Il Tribunale di prime cure aveva assolto gli imputati ritenendo non soltanto che l'evento occorso fosse imprevedibile, ma altresì che non sussistesse una posizione di garanzia fondata su norme di protezione civile. A seguito di ricorso per saltum proposto dal Procuratore Generale, la Suprema Corte annullava la sentenza con rinvio, formulando considerazioni in tema di giudizio di prevedibilità dell'evento di matrice squisitamente precauzionistica, che si compendiano nell'affermazione secondo la quale tale giudizio andava compiuto tenendo conto dell'esperienza del passato, "ma senza ignorare l'esistenza di una possibilità di evoluzione del fenomeno ed ipotizzando, quindi, la più distruttiva ipotesi che potesse verificarsi o che il fenomeno disastroso poteva comportare" 24 .

L’obbligo di prevedere l'imprevedibile, tipica pretesa riservata nell'antichità ai possessori di arti divinatorie, pone il soggetto chiamato a gestire la fonte di rischio innanzi ad una solitudine che appare intollerabile alla luce dei canoni di legalità e colpevolezza, quali cifre costitutive dell'ortodossia del rimprovero colposo, declinato in una dimensione sovranazionale e nazionale ${ }^{25}$.

\section{Prevedibilità della decisone giudiziaria nella lente della creatività e del creazionismo}

Dinnanzi a decisioni che sempre più si discostano dal parametro legale che determina i limiti applicativi della fattispecie incriminatrice, le più autorevoli voci della dottrina italiana invitano a indagare i rapporti fra creazionismo - creatività della giurisprudenza e prevedibilità della decisone giurisdizionale ${ }^{26}$.

È bene precisare, sin da subito, come la misura di questa relazione dipenda, in modo univoco, dal coefficiente di scientificità che sorregge la decisione giurisprudenziale.

Vediamo perché.

\footnotetext{
${ }^{24}$ In questa sede i giudici formulano un principio di diritto che sarà costantemente richiamato in tutte le successive sentenze di condanna per disastri naturali: Se di un fenomeno naturale (o anche cagionato dall'uomo) non si conoscono le caratteristiche fondamentali - in particolare le cause, le possibilità di evoluzione, gli effetti possibili - la cautela che occorre usare nell'affrontarlo per eliminarne o ridurne le conseguenze deve essere ancora maggiore proprio perché non si possono escludere, con valutazione ex ante fondata su conoscenze scientifiche affidabili, gli effetti maggiormente distruttivi”.

${ }^{25}$ Esprime parole di assoluta criticità STELLA, F. (2002), Verità, scienza e giustizia: le frequenze medio - basse nella successione di eventi, in Riv. it. dir. proc. pen., p. 1218, il quale afferma che "è precisamente a questa visone del processo penale, fondata sull'arbitrio e solidale con una concezione autoritaria della Stato, che si sono ispirate le numerose e ben note pronunzie giurisprudenziali in tema di rischi creati dall'attività produttiva o legati a pratiche sociali come all'attività medico chirurgica: poiché ciò che conta non è la verità delle premesse giuridiche, ma la verità materiale, costituita da comportamenti negligenti o gravemente negligenti dell'imprenditore o del medico, il giudice spesso non esita a rivestire i panni del legislatore ed emana delle sentenze di condanna che manipolano il requisito della causalità fino al punto di farlo coincidere con la colpa".

${ }^{26}$ DALFINO, D. (2018), Creatività e creazionismo, prevedibilità e predittività, in Foro It., V, p. 385.
} 
Come correttamente sottolineato, la giurisprudenza può essere, entro certi limiti, “creativa” ma non può essere "creatrice”, "poiché la creatività appartiene ad una capacità della ragione, la creazione all'atto di far nascere dal nulla" 27 .

Lo slancio “creazionista” della giurisprudenza deve essere fortemente stigmatizzato quando esso, proprio come accade con il rimprovero colposo, si invera ne "la tendenza di alcuni giudici a produrre norme, ad autoproclamarsi fonte del diritto, a fondare la decisone non tanto sull'interpretazione di un testo o sull'individuazione del suo significato (alle quali giammai rinunciano formalmente ma delle quali dichiarano il limite che ne giustifica l'abbandono), quanto su principio o sul valore estrapolato da un contesto. Il giudice creazionista va oltre il testo, ma non necessariamente per sublimarne la portata bensì, spesso, per pretermetterla” ${ }^{28}$.

Il giudice, chiamato a formulare quella prognosi di prevedibilità dell'evento che sola può fondare il rimprovero a titolo di colpa, talvolta non si sottrae alla tentazione di creare una regola cautelare ad hoc oppure di interpretare la regola di diligenza preesistente, rigida o elastica che sia, dotandola di uno spettro cautelare esteso a fatti oggettivamente non preconizzabili dall'agente.

La creazione della cautela rappresenta la più fulgida epifania del creazionismo giurisprudenziale che rompe l'alleanza, se mai vi sia stata, fra chi, anche per motivi istituzionali, è chiamato a gestire il rischio e chi, per gli stessi motivi, è chiamato a controllare la corretta applicazione dei precetti primari e secondari.

L'attività di ius dicere, la sola che possa compete al giudice ai sensi dell'art. 101, comma 2, Cost., si trasforma nell'enunciazione di profili valoriali discrezionali che celano e nemmeno troppo bene, afflati giustizialisti dalle indubbie suggestioni liberticide.

Come ricorda autorevole dottrina "Il 'pensare (e decidere) per valori'-, come che siano intuiti, immanenti o trascendenti, calati dall'alto o emersi dal basso -, è altezzoso soggettivo concreto. Il Giurista dei 'valori’ innalza a valore ciò che fa 'valere' con l'energia della propria volontà, o d'una volontà comune a sé o ad altri (Nietzsche ci ha svelato questi percorsi interiori). Egli si pone difronte alla 'situazione di vita' e risponde con la concreta immediatezza di un valore. La decisone della controversia non è più un caso di applicazione normativa, ma una occasione di realizzare il valore, di esprimere un incalcolabile giudizio di approvazione o disapprovazione"29.

Niente a che vedere, ovviamente, con quell'attività creativa che, contenuta nei parametri della stretta legalità e della colpevolezza può assicurare interpretazioni evolutive di norme obsolete o di cautele superate, magari attraverso una denuncia stigmatizzante di tali fenomeni ai quali tuttavia può porre rimedio soltanto il legislatore.

$\mathrm{Al}$ contrario, il creazionismo giurisprudenziale che affetta, oggi più che mai il rimprovero colposo, frammenta il percorso giurisprudenziale, finendo inoltre per impedire il perseguimento di quell'esigenza di prevedibilità delle decisioni giurisdizionali che sola può garantire il rispetto del canone di uguaglianza sancito dall'art. 3 Cost. ${ }^{30}$

È bene peraltro precisare come qui, attraverso la critica rivolta al creazionismo, non si intenda, per converso, valorizzare la prevedibilità di una decisone

\footnotetext{
${ }^{27}$ DALFINO, D. (2018), p. 386.

${ }^{28}$ DALFINO, D. (2018), p. 387.

${ }^{29}$ IRTI, N. (2016), Un diritto incalcolabile, Torino, p. 14.

${ }^{30}$ DALFINO, D. (2018), Creatività e creazionismo, prevedibilità e predittività, cit. p. 386.
} 
quale strumento volto al soddisfacimento delle istanze capitalistiche di certezza che si inverano nella calcolabilità delle conseguenze assunte nelle scelte rischiose.

Parimenti, non si vuole negare che lo ius dicere, incarnandosi nella "presa di posizione dinanzi ad un episodio di vita", rappresenti una dimensione gnoseologica necessariamente legata alla fenomenologia del caso concreto ${ }^{31}$.

Piuttosto, si vuole denunciare come l'incontro del diritto con il fatto non possa dar luogo a quell'"incalcolabile soggettivismo della decisone" che assoggettando la regola cautelare, rigida o elastica che sia, alle esigenze dettate dalla contingenza del momento, alle esigenze giustizialiste del clima politico e sociale, trasformi la decisone giudiziaria in arbitrio ${ }^{32}$.

La rottura che si consuma fra diritto e scienza tradisce la vera vocazione del diritto che, come ricordato da autorevole dottrina, "per sua natura ha la pretesa di dominare l'imprevedibile ... di impossessarsi di fatti non ancora compiuti. Il diritto non vuole salvare il passato ma conquistare il futuro: l'irretroattività è soltanto l'altro lato di questa chiamata verso il domani”33.

Un domani che, ove si negasse il ruolo primario della scienza nella ricostruzione del fatto sub iudice, incuterebbe davvero timore ${ }^{34}$.

\section{LA RISPOSTA DELLA GIURISPRUDENZA ALLA DOMANDA DI PREVEDIBILITÀ}

A ben vedere, del pari di quanto accade in relazione ad ogni fenomeno sociale, dobbiamo prestare attenzione alle gravi storture che si sono consumate nel passato e muovere da queste per ricostruire, assieme alla più attenta dottrina che da anni ormai le denuncia $^{35}$, un futuro nel quale il coefficiente di incertezza insito in ogni ambito scientifico non rappresenti più una minaccia per chi si trovi nelle già nelle impietose mani della Giustizia.

\section{I difficili rapporti fra scienza e prevedibilità dell'evento: dalla sentenza di "Porto Marghera" alla recente pronuncia sui fatti delle "Macalube di Aragona”.}

\footnotetext{
${ }^{31}$ IRTI, N. (2014), La crisi della fattispecie, in Riv. dir. proc., p. 43; ID, (2014), Calcolabilità weberiana e crisi della fattispecie, in Riv. dir. civ., p. p. 987.

${ }^{32}$ Parla di "incalcolabile soggettivismo della decisone” IRTI, N. (2016), Un diritto incalcolabile, cit., p. 8.

${ }^{33}$ IRTI, N. (2016), p. 19.

${ }^{34}$ In merito alle considerazioni fatte fino ad ora occorre ricordare come autorevoli penalisti si sono occupati del rapporto fra diritto civile e diritto penale con riferimento all'imputazione colposa. In particolare si ricorda come "gli stessi civilisti, del resto, finiscono per riconoscere, di nuovo alle regole di diligenza un'efficace attitudine al controllo dei rischi, allorchè assegnano al diritto penale il compito di presidiarne l'osservanza e di sanzionarne la violazione; e sono ancora una volta gli stessi civilisti a restituire "utilità" ed efficacia preventiva alle svalutate regole di diligenza, allorché caldeggiano il ricorso al meccanismo del rialzo dei premi assicurativi come incentivo al rispetto di quelle regole" così MARINUCCI G., (2012), Il ruolo delle regole scritte di diligenza nell'era dello sviluppo tecnico, cit., p. 297.

${ }^{35}$ PIERGALLINI, C. (2005), Paradigma della colpa nell'età del rischio: prove di resistenza del tipo, cit., p. 1699.
} 
Un ruolo particolarmente stigmatizzante deve certamente essere conferito alla già richiamata sentenza Bartalini ${ }^{36}$ la quale, nel determinare se la morte dei lavoratori per mesotelioma pleurico fosse una conseguenza prevedibile dell'utilizzo del CVM da parte degli imputati, ritiene, sulla scorta di altra nota e precedente giurisprudenza la quale ritiene che "ai fini del giudizio di prevedibilità, deve aversi riguardo alla potenziale idoneità della condotta a dar vita ad una situazione di danno e non anche alla specifica rappresentazione ex ante dell'evento dannoso, quale si è concretamente verificato in tutta la sua gravità ed estensione" ${ }^{37}$. All'interrogativo circa la latitudine di questa prevedibilità, i giudici rispondono ritenendo sufficiente che l'imputato possa rappresentarsi "una categoria di danni sia pure indistinta”, che avrebbe dovuto indurlo ad astenersi dalla condotta o spingerlo ad adottare più sicure regole di prevenzione. L'accoglimento di una tesi così profondamente distorsiva dei contorni del rimprovero colposo si fonda sulla considerazione (alla luce del senno di poi) della potenzialità lesiva della sostanza nociva.

La Corte, infatti, si domanda quali siano i criteri che devono governare l'accertamento della potenzialità lesiva prevedibile. E, in proposito, statuisce un principio di diritto foriero di una completa mistificazione dei concetti di rischio, pericolo, prevedibilità (e financo evitabilità) del delitto colposo ${ }^{38}$.

Una tradizione giurisprudenziale di simile tenore non ha potuto non contagiare altri settori del rischio. La circostanza appare in tutta la sua evidenza nell'ordito della motivazione del Tribunale di Agrigento il quale si è pronunciato sulle responsabilità in merito al tragico decesso di due minori travolti e uccisi dal fango, fuoriuscito dall'esplosione di un vulcanello, nella Riserva naturale integrale delle "Macalube di Aragona”.

Per il fatto erano tratti a giudizio il direttore della riserva naturale integrale "Macalube di Aragona” il custode dell'area, incaricato dal direttore di effettuare il monitoraggio e il dirigente responsabile del settore "Gestione e affari relativi alle aree naturali protette” del Dipartimento regionale Ambiente della Regione Sicilia.

Tutti i soggetti erano imputati del delitto previsto e punito dagli artt. 113, 40 cpv., 589 e 61 n. 3 perché cooperando colposamente tra di loro, ciascuno consapevole della condotta negligente ed imperita dell'altro, cagionavano la morte di due bambini determinata dal c.d. ribaltamento della collina dei vulcanelli all’interno della zona A

\footnotetext{
${ }^{36}$ Cass. pen. sez. IV, 17 maggio 2007, cit.

${ }^{37}$ Cass., pen. sez. IV, sentenza 6 dicembre 1990, Bonetti, rv. 191791, relativa al disastro di Stava. Queste conclusioni sono state ribadite da Cass. pen. sez. IV, 31 ottobre 1991, Rezza, rv. 191809 ed espressamente richiamate da Cass. pen. sez. IV, 30 marzo 2000, Camposano, rv. 219423-8.

38 "Su questo punto questa Corte ritiene non possano esservi dubbi sulla correttezza della tesi fatta propria dalla sentenza impugnata secondo cui le regole di spiegazione causale dell'evento non possono valere per l'accertamento dell'esistenza della colpa. La soglia - insita nei concetti di diligenza e prudenza espressamente richiamati dall'art. 43 c.p. - oltre la quale l'agente può prevedere le conseguenze lesive della sua condotta, non è costituita dalla certezza scientifica ma dalla probabilità o anche della sola possibilità (purché fondata su elementi concreti e non solo congetturali) che queste conseguenze si producano.

Naturalmente questa possibilità deve essere concreta e non solo astratta. È questo il limite che differenzia le situazioni in cui le pubbliche autorità devono intervenire per la salvaguardia dell'ambiente o per la tutela della vita e della salute dei consociati dalle situazioni in cui viene in considerazione l'agire del singolo soggetto: la concretezza del rischio. E il rischio diviene concreto quando - sia pure in base a ricerche non ancora complete o prive di requisiti di generale applicabilità o anche soltanto in base a serie generalizzazioni empiriche - viene individuata la possibilità dell'idoneità lesiva di una condotta commissiva od omissiva che dunque diviene prevedibile”.
} 
della riserva naturale integrale delle Macalube di Aragona, istituita con decreto assessoriale n. 290 del 1944 e concessa in gestione a Legambiente.

Il Tribunale di Agrigento riteneva responsabili dell'omicidio colposo D.F. e D.G condannandoli rispettivamente a 6 anni e 5 anni e 3 mesi di reclusione e disponendo per entrambi l'interdizione dai pubblici uffici. Il Tribunale assolveva F.G. perché "il fatto non costituisce reato" 39 .

La sentenza si rivela di grandissimo interesse poiché intende definire le responsabilità penali relative alle conseguenze di un fenomeno naturale sul quale non esiste letteratura scientifica.

Infatti, esaminate le "fonti conoscitive del fenomeno geologico delle Macalube di Aragona”, il giudice sottolinea: "tutti gli scienziati escussi in dibattimento" concordano nel ritenere che, pur essendo noto il fenomeno di manifestazione esterna del fenomeno, sconosciute rimangono tuttavia le ragioni che innescano la risalita improvvisa dei gas verso la superficie. Non è possibile, infatti, associare le Macalube ad altre manifestazioni naturali, ancorché simili a livello fenomenologico. Solo attraverso uno studio prolungato del fenomeno si potrebbe addivenire alla individuazione dei possibili fattori scatenanti e dei possibili precursori dell'evento, ma questo studio non è stato mai compiuto ${ }^{40}$.

La mancanza di una più accurata indagine scientifica deve attribuirsi anche alla convinzione della scarsa pericolosità dei vulcanelli che, sino al settembre del 2014, data del tragico evento oggetto della cognizione del giudice, non aveva mai cagionato vittime.

Inoltre, nei giorni precedenti all'evento non vi era stata alcuna avvisaglia di possibili anomalie geologiche.

Sebbene il dibattimento abbia appurato, dunque, che non si conoscono né la fenomenologia né le modalità di innesco del fenomeno ${ }^{41}$, ed altresì che non si era mai verificato un evento di tale portata in danno ad un visitatore, né che in quel momento fossero in atto dei precursori riconoscibili, il giudice ha ritenuto che il tragico evento occorso ai due piccoli visitatori non fosse fortuito bensì pienamente prevedibile ${ }^{42}$.

Così, riconosciuta la sussistenza di una posizione di garanzia del direttore e del custode del Parco rispetto alla vita e all'incolumità fisica dei visitatori, il giudice ha statuito la responsabilità colposa degli imputati proprio in ragione della conoscibilità del pericolo e della prevedibilità dell'evento. ${ }^{43}$

Orbene, anche volendo censurare il comportamento del direttore del parco il quale non aveva predisposto cartelli che indicassero il comportamento da tenere in concomitanza di un evento parossistico e restrizioni di accesso alle zone ritenute più pericolose, l'assenza di una legge scientifica idonea a spiegare i precursori e le forme di manifestazione del fenomeno delle Macalube rende impossibile stabilire se queste misure, una volta adottate, avrebbero potuto impedire l'evento. Manca, quindi, l'indicazione di un comportamento alternativo lecito quale fattore di evitabilità dell'evento.

Infatti, la fragilità della ricostruzione accusatoria si manifesta nella sua interezza dove il giudice ritiene di elevare a comportamento doveroso la chiusura della

\footnotetext{
39 Tribunale di Agrigento, 13 giugno 2018, Giudice Dott. Caruso. Inedita.

40 Pag. 6 della sentenza.

${ }^{41}$ Pagg. 44 e 46 della sentenza.

42 Pag. 42 della sentenza.

43 Pagg. 58-60 della sentenza.
} 
riserva, sine die, in assenza di dati sulla pericolosità del fenomeno. Come nelle sentenze relative all'utilizzo industriale dell'amianto o del disastro di Sarno, anche qui, in ossequio al principio di precauzione, si afferma la doverosità di adottare una cautela astensionistica la quale ci si permetta di notare, non compete al direttore di un'aera naturale, ma all'organo politico che ne conferisce la gestione ${ }^{44}$.

Assolutamente non condivisibile appare, inoltre, la condanna del custode dell'area, al quale era demandata l'osservazione dei fenomeni precursori e l'obbligo di comunicazione al direttore $^{45}$. Se fenomeni precursori non ve ne erano, qual è la condotta omissiva posta alla base dell'aumento del rischio (paradigma causale da più parti ritenuto inaccettabile, ma tanto amato dalla giurisprudenza)?

\section{Le voci della speranza: la ricostruzione delle responsabilità per l'alluvione di Olbia alla luce di un agente modello in chiave assolutoria}

Nella speranza che il giudizio di Appello ${ }^{46}$ possa valorizzare correttamente il ruolo che l'assenza di legge scientifiche, di precedenti e di precursori determina sulla possibilità di configurare un giudizio di responsabilità per colpa nei tragici fatti delle "Macalube di Aragona", appare tuttavia importante dar conto anche di quella giurisprudenza, sempre di merito, la quale ha in modo del tutto condivisibile, escluso le responsabilità in capo al Sindaco di Olbia, al Sindaco di Arzachena, al Responsabile del Servizio di Protezione civile del Comune di Olbia, al Dirigente Settore Ambiente e Autorità Istituzionale di Protezione Civile dell'Ente Provincia di Olbia-Tempio, al Dirigente Settore tecnico Manutenzioni del Comune di Olbia nonché al Dirigente Settore tecnico - Assessorato ai lavori pubblici del Comune di Olbia per i tragici decessi occorsi in occasione dell'alluvione di Olbia e Arzachena del novembre $2013^{47}$.

Tutti questi soggetti erano imputati del delitto dell' artt. 61 n. 9, 113, 449 c.p. perché, secondo l'accusa, esponevano un numero indeterminato di cittadini di Olbia e Arzachena a grave pericolo di incolumità fisica, omettendo, per negligenza, di svolgere attività di prioritaria importanza per la protezione civile della popolazione esposta al rischio di alluvione nei Comuni di Olbia e Arzachena, occorsa in data 17 e 18 novembre 2013.

Il Dirigente Settore Ambiente e Autorità Istituzionale di Protezione Civile dell'Ente Provincia di Olbia-Tempio e il Sindaco di Arzachena erano altresì accusati di omicidio colposo plurimo giacché, sempre secondo l'accusa, contribuivano a cagionare

\footnotetext{
44 Di recente la giurisprudenza è tornata a ribadire l'importanza del principio di precauzione nella responsabilità penale per l'utilizzo di sostanze tossiche. In proposito si veda Cass. pen. sez. IV, 15 maggio 2018, n. 46932, in DeJure. In tema di disastri naturali si veda invece Cass. pen. sez. IV, 29 marzo 2018, n. 14550 in www.Leggiditaliaprofessionale.it.

45 Sugli obblighi di comunicazione di fenomeni rischiosi si veda, per tutti, nella letteratura sociologica, CERASE, A. (2017), Rischio e comunicazione. Teorie, modelli, problemi, Torino.

${ }^{46} \mathrm{Al}$ momento in cui il volume va in stampa il processo è pendente presso la Corte d’Appello di Palermo.

47 Tribunale di Tempio Pausania, 29 settembre 2017, n. 772, Rel. Dott. Pastori, inedita. A ben vedere, un altro esempio di ingresso della buona scienza nel processo, pur non penale, riguarda il famigerato caso Stamina. Fra le sentenze che rigettarono i ricorsi ex art. 700 c.p.c. delle parti che chiedevano potesse praticarsi con urgenza la c.d. infusione di cellule staminali, spicca il Decreto di rigetto del Tribunale di Torino, 10 marzo 2014, n. 5647, giud. Ciocchetti, che contiene un decalogo di regole attraverso le quali si possono individuare “i ciarlatani della salute”. La sentenza, oggetto di studio da parte dell’Ufficio della Senatrice a vita Elena Cattaneo, è disponibile su www.senato.it.
} 
per colpa la morte per annegamento di altre quattro persone, "con l'aggravante della violazione dei doveri inerenti la pubblica funzione rispettivamente esercitata”.

I giudici di prime cure, con atteggiamento argomentativo ben diverso quello tenuto dal giudice monocratico di Agrigento, giungono a stabilire quella corretta corrispondenza logica fra imprevedibilità - inevitabilità dell'evento e assenza di un rimprovero colposo in capo agli imputati.

In particolare, il Tribunale afferma che il tenore degli accadimenti, mai manifestatosi in quella portata, rendeva imprevedibile quell'esito nefasto poi verificatosi. Ne discende come, ai sensi dell'art. 41 secondo comma c.p. debba ritenersi interrotto il nesso causale fra la condotta degli imputati e il decesso dei soggetti ${ }^{48}$.

Appare evidente come queste statuizioni siano articolate secondo un paradigma logico-giuridico diametralmente opposto a quello utilizzato dalla Suprema Corte nella sentenza di annullamento con rinvio dell'assoluzione pronunciata nei confronti del sindaco di Sarno. In quella decisione, infatti, la l'assenza, nella storia del territorio, di un evento del tenore di quello occorso, aveva indotto la Corte ad affermare che il sindaco avrebbe dovuto assumere un atteggiamento ancor più prudente di quanto effettuato. Proprio in quel deficit di prudenza si annida la responsabilità colposa che i giudici di secondo grado avrebbero dovuto valutare (e che poi hanno ritenuto sussistente $)^{49}$.

Nel caso che occupa la nostra disamina, invece, financo il parametro dell'agente modello è utilizzato in funzione assolutoria. Infatti, il Tribunale, dopo aver misurato sulla base di tale parametro il complesso delle conoscenze disponibili al momento, ritiene che non potessero ascriversi agli imputati profili di responsabilità. Anzi, i giudici hanno affermato come occorra "fornire un giudizio favorevole in merito alla quantità e qualità degli sforzi da ciascuno fatti per prevenire prima, ed arginare poi, i danni portati dalla perturbazione ..." 50 .

Piuttosto, il Tribunale suggerisce apertamente che le responsabilità per i tragici eventi fossero da ricondursi al mancato operato della Regione Sardegna in persona dei suoi funzionari incaricati del coordinamento delle attività di Protezione Civile i quali, tuttavia, non sono stati coinvolti nel procedimento penale ${ }^{51}$.

\section{DALLA PREVEDIBILITÀ DELL'EVENTO AI DOVERI PRECAUZIONISTICI}

Nonostante alcune rare e pregevoli sentenze che riconoscono i limiti della preconizzabilità dell'evento da parte del soggetto garante della vita e dell'incolumità altrui, si assiste in modo costante ad un processo ricostruttivo delle responsabilità che nega la complessità dei fenomeni e degli aspetti procedurali deputati ad affrontali, riversando le conseguenze penali sul singolo operatore.

Il processo di reductio ad unitatem (rectius di banalizzazione) compiuto in sede di accertamento della rimproverabilità del fenomeno occorso assume, talvolta, una veste paradossale e determina la negazione di due presupposti fattuali nei quali si muove l'evento (di danno o di pericolo) che raramente sono passibili di smentita.

\footnotetext{
${ }^{48}$ Pag. 12 della sentenza.

${ }^{49}$ Ritenuta poi sussistente anche in Cassazione. Così Cass. pen. sez. III, 07 maggio 2013, n.19507, Est. Ramacci, in DeJure.

50 Tribunale di Tempio Pausania, cit., p. 14.

${ }^{51} \mathrm{Il}$ processo è attualmente pendente presso la Corte d'Appello di Sassari.
} 
In primo luogo, infatti, il processo di risk assessment e di risk management si configura come processo plurale, collettivo, articolato in sezioni funzionali delle quali sono responsabili soggetti diversi, chiamati ad interagire in modo necessario e secondo le loro specifiche competenze per fronteggiare il rischio ${ }^{52}$.

A tale proposito ed in via del tutto esemplificativa, possiamo ricordare come lo stesso legislatore abbia disposto che taluni rischi, particolarmente ricorrenti e di forte impatto sulla popolazione, debbano essere affrontati necessariamente attraverso un sistema sinergico di soggetti, ciascuno dotato di una posizione di garanzia nel proprio ambito di competenza. Fulgidi esempi si riscontrano nella disciplina della Protezione Civile (d.lgs. n. 1 del 2018) e della salute e sicurezza sul lavoro (d.lgs. n. 81 del 2008).

La stessa responsabilità amministrativa degli enti per i reati commessi dai soggetti ad essi legati da un rapporto di lavoro subordinato o apicale richiede la predisposizione di un modello organizzativo nel quale il rischio reato deve essere fronteggiato, presumibilmente, da sistemi che presuppongono l'interazione di processi di controllo presidiati da più soggetti diversi ${ }^{53}$.

In secondo luogo, la negazione della complessità dei fenomeni conduce ad effetti paradossali dove essa investe la individuazione della legge scientifica propria del fenomeno che costituisce oggetto della cognizione giurisdizionale ${ }^{54}$.

\footnotetext{
${ }^{52}$ Sul tema, per tutti, ricordiamo MORGANTE, G. (2010), Spunti di riflessione sul diritto penale e sicurezza del lavoro nelle recenti riforme legislative, in Cass. pen., p. 3319 e DE FRANCESCO, G. (2012), L'imputazione della responsabilità penale in campo medico-chirurgico: un breve sguardo d'insieme, in Riv. it. med. Leg., p. 970. Si veda inoltre PERIN, A. (2012), Colpa penale relazionale e sicurezza nei luoghi di lavoro, in Dir. pen. cont., p. 10.

53 Sulla responsabilità dell'ente, in via meramente esemplificativa, FERRARA, F. (2014), La responsabilità delle persone giuridiche, in Riv. dir. com., p. 513; BRICOLA, F. (1970), Il costo del principio "societas delinquere non potest" nell'attuale dimensione del fenomeno societario, in Riv. it. dir. proc. pen., p. 951 ss.; ORESTANO, R. (1978), "Persona" e "persone giuridiche" nell'età moderna, in Azioni, Diritti soggettivi, persone giuridiche, p. 209; FALZEA, A. (1981), La responsabilità penale della persona giuridica, in AA.VV. La responsabilità penale delle persone giuridiche in diritto comunitario, $\mathrm{p}$. 149; ALESSANDRI, A. (1983), Reati d'impresa e modelli sanzionatori, Milano; PALIERO, C.E. (2001), Il d.lgs. 8 giugno 2011, n. 231: da ora in poi societas delinquere (et puniri) potest, in Corr. giur., p. 845; ROMANO, M. (2002), La responsabilità amministrativa degli enti, società o associazioni. Profili generali, in Riv. Soc., p. 303; MARINUCCI, G. (2002), "Societas puniri potest" uno sguardo sui fenomeni e sulle discipline contemporanee, in Riv. it. dir. proc. pen., p. 1193; LANCELLOTTI, G. (2003), La responsabilità delle società per il reato dell'amministratore, Torino; PALAZZO, F. (2003), Societas puniri potest, La responsabilità da reato degli enti collettivi, Padova; PADOVANI, T. (2004), Il nome dei principi e il principio dei nomi: la responsabilità "amministrativa" delle persone giuridiche, in DE FRANCESCO, G. (a cura di), La responsabilità degli enti: un nuovo modello di giustizia punitiva, Torino; SANTI, F. (2004), La responsabilità delle società e degli enti, Milano; GARGANI, A. (2006), Individuale e collettivo nella responsabilità della societas, in St. sen., p. 273; GUERRINI, R. (2006), La responsabilità da reato degli enti, Milano; DE VERO, G. (2008), La responsabilità penale delle persone giuridiche, Milano; BERNASCONI, A. (2008), (voce) Responsabilità amministrativa degli enti (profili sostanziali e processuali), in Enc. Dir. Annali, Milano, p. 961; D’AVIRRO, A., - DI AMATO, A. (2009), La responsabilità da reato degli enti, Padova; LATTANZI, G. (2010), Reati e responsabilità degli enti, Milano; DE SIMONE, G. (2012), Persone giuridiche e responsabilità da reato. Profili storici, dogmatici e comparatistici, Pisa; SCOLETTA, M. M. (2014), La responsabilità da reato delle società: principi generali e criteri imputativi del d.lgs. 231/2001 in CERQUA, L. D. - CANZIO, G.- LUPARIA, L. (a cura di), Diritto penale delle società, Padova, p. 46.

Sulla compatibilità del modello prescelto dal legislatore del 2001 con il principio di colpevolezza ROMANO, M. (1995), Societas delinquere non potest (nel ricordo di Franco Bricola), in Riv. it. dir. proc. pen., p. 1037.

${ }^{54}$ Questo soprattutto perché, come ritiene anche la Dottrina non penalistica, "il processo rappresenta ... uno dei luoghi in cui si sperimenta la costituzione di una nuova conoscenza, derivante dalla definizione
} 
Chiunque si sia trovato ad occuparsi di una questione che attiene alle conseguenze dannose o pericolose legate a fenomeni naturali, avrà sicuramente fatto esperienza della pluralità di tesi che insistono, non solo diacronicamente, ma spesso sincronicamente, sulla etiologia delle stesse.

La compresenza di tesi opposte, lungi dal paralizzare la possibilità per il giudice di decidere secondo i canoni dettati dalla miglior scienza ed esperienza del momento storico, deve però agire necessariamente su due fronti, ovvero sul criterio di imputazione colposa e sul criterio di giudizio.

Come criterio di giudizio, la scelta effettuata dal giudice in ordine alla ricostruzione epistemologica deve corroborare un quadro probatorio valido oltre ogni ragionevole dubbio.

Come criterio di imputazione, può darsi che la complessità che caratterizza alcuni settori scientifici sia destinata a mutare in modo sostanziale il volto del rimprovero colposo per come lo conosciamo.

Proviamo a dimostrane i motivi.

Quando più leggi scientifiche, anche tra di loro contraddittorie, si contendono la spiegazione causale di un fenomeno e tutte sono parimenti valida e attuali, occorre riflettere sulla reale possibilità di esigere dal garante non soltanto la previsione dell'evento, poi occorso, ma altresì la dominabilità dei fattori di rischio idonei a produrre risultati offensivi nei confronti di beni giuridici primari, quali la vita e l'incolumità privata e pubblica ${ }^{55}$.

Infatti, la non infrequente compresenza di numerose leggi scientifiche che offrono spiegazioni diverse dei fenomeni naturali e delle loro conseguenze, non permette all'operatore del rischio di prevedere ed evitare, in modo univoco, l'evento, attraverso il normale percorso di scelta ed adozione una regola cautelare che possa dirsi ex ante realmente efficace.

In questi casi, ci sembra che il rimprovero colposo non possa neppure essere formulato, giacché, come detto, gli scienziati, le autorità o gli operatori di Protezione civile, lungi dal poter prevedere l'evento, potranno al più formulare degli scenari di rischio che non consentono l'adozione di cautele impeditive ${ }^{56}$.

normativa di verità scientifiche, come quelle relative alla pericolosità di una sostanza, e dalla costruzione epistemologica di concetti giuridici ... ma è anche il luogo che rivela il conflitto fra lo statuto della scienza e quello del diritto e in cui si oppongono un modello tecnocratico, in cui la scienza pretende di dire la verità al diritto e uno democratico, in cui il diritto pretende di controllare i meccanismi di costituzione delle verità scientifica attraverso un sistema di garanzie”, così. FODDAI, M. A. (2017), Controversie scientifiche e controversie giuridiche: i limiti della decisone giudiziale, in Politeia , p. 60.

${ }^{55}$ Qui il termine garante è utilizzato nell'accezione di "gestore del rischio", offerta dalla sentenza Cass. pen. sez. Un., 18 settembre 2014, n. 38343 in DeJure.

56 Ridimensiona il ruolo della prevedibilità dell'evento anche GIUNTA, F. (2019), Culpa culpae, cit. apparso su www.disCrimen.it dal 4 giugno 2019, [consultato il 13 giugno 2019] il quale afferma come "nella storia teorica della colpa la prevedibilità ha svolto una duplice funzione, rilevando, da un lato, come criterio diagnostico della situazione di pericolo che concretizza il dovere cautelare, dall'altro come base valutativa esperienziale e scientifica per la formazione della regole di comportamento doverosa, espressiva della c.d. evitabilità". Pur tuttavia, oggi nell'intento di ovviare al fenomeno dell'”'abnorme dilatazione della responsabilità colposa, si rende necessario un ripensamento del giudizio di prevedibilità, sia sotto il profilo della sua funzione, sia sotto quello della sua identità”. Così si sottolinea che “...il ruolo della prevedibilità merita di essere circoscritto; esso deve limitarsi ad operare come presupposto operativo della regola cautelare, ossia come condizione della sua doverosità”. In questo modo la prevedibilità assume il volto di una "enclave soggettiva nella tipicità oggettiva” (pp. 10 e 11). 
Questa impossibilità di formulare una previsione, che caratterizza i contesti scientifici propri dei più insidiosi rischi naturali, a ben vedere, più essere ulteriormente confermata o financo aggravata dalla insuperabile difficoltà per i garanti di conoscere i fattori esogeni che incidono sulla dimensione fenomenica di un evento naturale.

Infatti, alcune significative vicende giurisprudenziali legate alla gestione dei rischi naturali, hanno insegnato che il contesto fattuale in riferimento al quale scienziati e tecnici sono chiamati a prestare la propria opera è influenzato, in buona misura, da scelte politiche e amministrative che frammentano, in modo esponenziale e talvolta imponderabile, il novero dei presupposti sui quali si fonda tanto riconoscibilità del pericolo, quanto il processo di scelta delle cautele ${ }^{57}$.

Pensiamo alla non preconizzabilità degli effetti legati a politiche di gestione urbanistica (legittima o illegittima) del territorio delle quali non sia facile avere contezza, soprattutto nel momento di gestione dell'emergenza (come ad esempio accade per il ttombamento di corsi d'acqua nelle aree rurali). Questi, come altri fattori legati alla mancata adozione di corrette politiche di gestione del rischio, influenzano in modo assoluto l'applicazione della legge scientifica al caso concreto, alterando quella correlazione fra fenomeno naturale e conseguenze sulla popolazione che già faticosamente lo scienziato potrebbe ipotizzare in condizioni di minore complessità ${ }^{58}$.

Così, la moltiplicazione spesso incontrollata e non conoscibile delle scelte politico amministrative effettuate in ordine alla gestione del rischio altera lo scenario dei fenomeni e rompe la grigia semantica nella quale si articola il concetto di prevedibilità.

Quando l'incertezza connaturata alla maggior parte delle scienze naturali incontra l'incontrollata plurivocità delle scelte tecniche, la complessità dei presupposti di base costringe ad abbandonare il terreno della prevedibilità dell'evento in favore della mera formulazione di scenari di rischio ${ }^{59}$.

La restituzione della falsa prevedibilità al suo reale volto di scenario ipotetico dell'evento permette di comprendere quando possa essere o meno mosso il rimprovero per colpa.

Lo sa bene il legislatore dell'Unione europea, il quale innanzi a fenomeni dove la prevedibilità non può esistere o perché manca una solida legge scientifica di copertura, o perché un evento è influenzato da scelte politiche che ne investono i presupposti fenomenici, si rifugia nel principio di precauzione, ormai così di moda anche nelle nostre aule giudiziarie ${ }^{60}$.

\footnotetext{
${ }^{57}$ Soprattutto nella fase di emergenza.

${ }^{58}$ La prevedibilità si basa su modelli univoci frutto di scelte condivise nella comunità scientifica. Quando queste scelte dipendono da variabili esogene e per lo più frutto di scelte politiche, la scienza che vi si applica cessa di prevedere e inizia a formulare ipotesi le quali per la loro variabilità e scarsa pregnanza non possono costituire la base cognitiva per l'individuazione di una regola cautelare ${ }^{58}$.

La restituzione della falsa prevedibilità al suo reale volto di scenario ipotetico dell'evento permette di comprendere quando possa essere o meno mosso il rimprovero per colpa.

${ }^{59} \mathrm{E}$ forse, in questi casi, potrebbe residuare la responsabilità per la violazione di una fattispecie incriminatrice di pericolo, ove ne siano integrati gli elementi di tipicità.

${ }^{60}$ Sul principio di precauzione, per una riflessione più ampia, BARTOLOMMEI, S. (2001), Sul principio di precauzione: norma assoluta o regola procedurale?, in Bioetica, , p. 321; MARINI, G. (2004), Principio di precauzione, sicurezza alimentare e organismi geneticamente modificati nel diritto comunitario, Il Diritto dell'Unione Europea, p. 281. Di recente inoltre GIUNTA, F. (2006), Il diritto penale e le suggestioni del principio di precauzione, in Criminalia, p. 227; RUGA RIVA, C. (2006), Principio di precauzione e diritto penale. Genesi e contenuto della colpa in contesti di in- certezza
} 
Non è un caso infatti che l'art. 191 del Trattato sul Funzionamento dell’Unione Europea (art. 174 TCE $^{61}$ ) preveda, al comma 2,: “2. La politica dell'Unione in materia ambientale mira a un elevato livello di tutela, tenendo conto della diversità delle situazioni nelle varie regioni dell'Unione. Essa è fondata sui principi della precauzione e dell'azione preventiva, sul principio della correzione, in via prioritaria alla fonte, dei danni causati all'ambiente, nonché sul principio "chi inquina paga".

In tale contesto, le misure di armonizzazione rispondenti ad esigenze di protezione dell'ambiente comportano, nei casi opportuni, una clausola di salvaguardia che autorizza gli Stati membri a prendere, per motivi ambientali di natura non economica, misure provvisorie soggette ad una procedura di controllo dell'Unione”.

scientifica, in Studi in onore di Giorgio Marinucci, Milano, p. 1743; FORTI, G. (2006), Accesso alle informazioni sul rischio e responsabilità: una lettura del principio di precauzione, in Criminalia, p. 155; ID (2007), La chiara luce della verità e l'ignoranza del pericolo. Riflessioni penalistiche sul principio di precauzione, in AA. VV. (a cura di) Scritti per Federico Stella, Napoli, p. 573; CONSORTE, F. (2007), Spunti e riflessioni sul principio di precauzione e sugli obblighi di tutela penale, in Dir. Pen. XXI secolo, p. 271; DE LEONARDIS, F. (2007), Il principio di precauzione nell'amministrazione di rischio, Milano, p. 48; PONGILUPPI, A. (2010), Principio di precauzione e reati alimentari, in Riv. trim. dir. pen. econ., p. 260; CONSORTE, F. (2011), Principio di precauzione e beni legati alla sicurezza. La logica precauzionale come fattore espansivo del penale nella giurisprudenza della Cassazione, in www.penalecontemporaneo.it, oggi confluito in GRASSO, G. - PICOTTI, M.- SICURELLA, R. (a cura di), L'evoluzione del diritto penale nei settori d'interesse europeo alla luce del Trattato di Lisbona, Milano, 2011; CASTONUOVO, D. (2012), Principio di precauzione e diritto penale, Roma; SCORDAMAGLIA, I. (2012), Il diritto penale della sicurezza del lavoro tra i principi di prevenzione e di precauzione, in $w w w$. penalecontemporaneo.it, 23 novembre 2012 [consultato il 13 giugno 2019]; CORN, E., Il principio di precauzione nel diritto penale, Torino, 2013. Di notevole importanza anche GIUNTA, F. (2008), voce Principio di precauzione, in ID (a cura di), Dizionario di Diritto penale, Milano, Il Sole 24 Ore, p. 905 ss., nonché, certamente, EWALD, F. (2001), Philosophie politique du principe de précaution, Gollier, p. 21. Sul sostrato giuridico del principio di precauzione come risposta alla paura della società v. JONAS, H. (1979), Das Prinzip Verantwortung, Frankfurt am Main, tr. It. Il principio della responsabilità. Un' etica per la civiltà tecnologica. Torino, 1993, passim.

61 “1. La politica dell'Unione in materia ambientale contribuisce a perseguire i seguenti obiettivi:

a) salvaguardia, tutela e miglioramento della qualità dell'ambiente,

b) protezione della salute umana,

c) utilizzazione accorta e razionale delle risorse naturali,

d) promozione sul piano internazionale di misure destinate a risolvere i problemi dell'ambiente a livello regionale o mondiale e, in particolare, a combattere i cambiamenti climatici.

2. La politica dell'Unione in materia ambientale mira a un elevato livello di tutela, tenendo conto della diversità delle situazioni nelle varie regioni dell'Unione. Essa è fondata sui principi della precauzione e dell'azione preventiva, sul principio della correzione, in via prioritaria alla fonte, dei danni causati all'ambiente, nonché sul principio "chi inquina paga".

In tale contesto, le misure di armonizzazione rispondenti ad esigenze di protezione dell'ambiente comportano, nei casi opportuni, una clausola di salvaguardia che autorizza gli Stati membri a prendere, per motivi ambientali di natura non economica, misure provvisorie soggette ad una procedura di controllo dell'Unione.

3. Nel predisporre la sua politica in materia ambientale l'Unione tiene conto:

a) dei dati scientifici e tecnici disponibili,

b) delle condizioni dell'ambiente nelle varie regioni dell'Unione,

c) dei vantaggi e degli oneri che possono derivare dall'azione o dall'assenza di azione,

d) dello sviluppo socioeconomico dell'Unione nel suo insieme e dello sviluppo equilibrato delle sue singole regioni.

4. Nell'ambito delle rispettive competenze, l'Unione e gli Stati membri collaborano con i paesi terzi e con le competenti organizzazioni internazionali. Le modalità della cooperazione dell'Unione possono formare oggetto di accordi tra questa ed i terzi interessati.

Il comma precedente non pregiudica la competenza degli Stati membri a negoziare nelle sedi internazionali e a concludere accordi internazionali”. 
Non è un caso neppure che uno dei principali settori nei quali il principio di precauzione ha trovato la sua applicazione sia quello ambientale ${ }^{62}$.

Il principio di precauzione stravolge i canoni del rimprovero colposo e la sua applicazione generale, come giustamente aveva preconizzato la Dottrina, ha finito per "scaricare sui singoli cittadini decisioni su situazioni di incertezza scientifica, certamente complesse, le quali, proprio per questa ragione dovrebbero competere principalmente alle istituzioni e non agli operatori privati, nemmeno quando questi ultimi siano soggetti economicamente forti e, come tali, i grado di affrontare il costo economico di una approfondita attività istruttoria" 63 .

Se il principio di precauzione "si atteggia principalmente a criterio di buon amministrazione", alla cui osservanza sono chiamati gli enti pubblici, l'attuale modalità applicativa di tale principio viola i canoni ortodossi della colpevolezza, giacché il cittadino viene di fatto investito "del compito disumano di trarre da ipotesi di latenza del rischio (già di per sé difficili da enucleare) regole concrete di diligenza atte ad intercettare lo spettro preventivo che sarà convalidato da future scoperte scientifiche $[\ldots]]^{64}$.

L’incertezza scientifica, infatti, non soltanto mette in serio dubbio la possibilità di riconoscere la sussistenza dei presupposti fattuali della condotta doverosa, ma altresì il profilo contenutistico del dovere di diligenza che deve essere attuato ${ }^{65}$. dell'evento.

Con buona pace della bontà del giudizio in ordine alla prevedibilità

Infatti, "la prevedibilità dell’evento, caratteristica della colpa secondo le elaborazioni correnti, è irriducibilmente diversa dalla mera congettura di pericolosità che la scienza non può né fondare, né smentire. L'una consiste in una valutazione di verosimiglianza, l'altra si risolve in uno dei tanti giudizi di non impossibilità che si possono formulare in situazioni di incertezza. Tra la sponda della verosimiglianza e quella della non impossibilità non vi sono ponti, ma un rapporto di radicale alterità”66.

\footnotetext{
${ }^{62}$ Sul rapporto fra diritto penale dell'ambiente e principio di precauzione BELL, A. H. -VALSECCHI, A. (2015), Il nuovo delitto di disastro ambientale: una norma che difficilmente avrebbe potuto essere scritta peggio, www.penalecontemporaneo.it, [consultato il 13 giugno 2019]; RUGA RIVA, C. (2015), Dolo e colpa nei reati ambientali, in www.penalecontemporaneo.it, 19 gennaio 2015, [consultato il 13 giugno 2019], p. 2 e ss.

${ }^{63}$ GIUNTA, F. (2008), Il diritto penale e le suggestioni del principio di precauzione, cit. p. 241.

${ }^{64}$ GIUNTA, F. (2008), p. 241.

65 Nella letteratura spagnola sul legame fra incertezza scientifica e principio di precauzione si veda ex multis ARROYO ALFONSO, M. S. (2018), Apuntes sobre la administrativización del derecho penal del medio ambiente, in Actualidad Jurídica Ambiental, n. 83, Sección “Artículos doctrinales”, 1ottobre 2018. ${ }^{66}$ GIUNTA, F. (2008), Il diritto penale e le suggestioni del principio di precauzione, cit. p. 242.
} 


\section{LEGGI SCIENTIFICHE ED EVITABILITÀ DELL'EVENTO}

La giurisprudenza ci mostra, inoltre, come la complessità del dibattito scientifico che favorisce l'applicazione del principio di precauzione investa anche il profilo della regola cautelare di diligenza la quale finisce per coincidere con un obbligo (ancorché temporaneo) di inazione ${ }^{67}$.

Ma la regola che impone l'astensione dalle attività rischiose non è, come sottolinea la dottrina, una regola cautelare ${ }^{68}$.

Anzi, ci sono casi nei quali l'astensione costituisce in sé condotta penalmente rilevante, come accade quando il soggetto sia gravato dall'obbligo giuridico di impedire l'evento. In questo caso, il soggetto deve porre in essere tutte le cautele disponibili, che siano espressione della miglior scienza ed esperienza del momento storico ${ }^{69}$.

La cautela prescelta può, tuttavia, rivelarsi insufficiente, errata o dannosa alla luce della verificazione dell'evento che l'agente ha cagionato o non è riuscito ad impedire.

A ben vedere, la complessità scientifica di taluni fenomeni acuisce, se possibile, il problema probatorio che attiene al grado di evitabilità dell'evento richiesto ai fini della determinazione della responsabilità colposa. Si tratta di una questione di già centrale rilevanza nel dibattito che involge (anche) la ricostruzione del nesso di causalità (specie se omissivo).

La stessa dottrina, consapevole delle difficoltà, si domanda "basta che il comportamento alternativo lecito sia accreditato di mere chances di successo, oppure occorre qualche cosa in più? L'imputazione normativa a titolo di colpa è esclusa solo se sia certo che l'evento non si sarebbe evitato? O, all'opposto, per ritenere integrata la tipicità la tipicità del fatto colposo d'evento, è necessaria addirittura la verifica che, in ipotesi di comportamento osservante delle regole di diligenza, l'evento sarebbe stato scongiurato con cuna probabilità “vicina a 100?”70

Il problema sorge dove con una prospettiva ex post il comportamento alternativo lecito si riveli probabilmente efficace o probabilmente inefficace.

Due le ipotesi ricostruttive avanzate.

Secondo una prima tesi, vi sarebbe una sostanziale identità fra causalità e causalità della colpa: "quando la condotta naturalistica tenuta da un certo soggetto coincide con la violazione di una regola di diligenza, il livello di probabilità logica della efficacia causale, rispetto all'evento verificatosi, di tale violazione si identifica con il livello di probabilità logica della efficacia causale relativa alla condotta. E nessuno discute che quel livello debba attestarsi, in sede di accertamento, su valori contigui al $100 \% " 71$.

Questa ricostruzione, espressione di un ampio e condivisibile rigore garantista, se da un lato impone all'accusa un onere probatorio quasi invalicabile,

\footnotetext{
${ }^{67}$ MANTOVANI, F. (2017), Diritto penale, cit. p. 333: “l'evitabilità dell'evento, con cui si individuano le regole cautelari, cioè prescrittive di modi comportamentali, osservando le quali la pericolosità della condotta è esclusa o contenuta”.

${ }^{68}$ GIUNTA, F. (2002), Principio e dogmatica della colpevolezza nel diritto penale d'oggi, in Riv. it. dir. proc. pen., p. 123.

${ }^{69}$ VENEZIANI, P. (2013), Causalità della colpa e comportamento alternativo lecito, in DONINI, M. ORLANDI, R. (a cura di), Reato colposo e modelli di responsabilità, Bologna, p. 298.

${ }^{70}$ VENEZIANI, P. (2013), p. 292 e 293.

${ }^{71}$ EUSEBI, L. (2000), Appunti sul confine fra dolo e colpa nella teoria del reato, in Riv. it. dir. proc. pen., p. 1064.
} 
dall'altro finisce forse per ignorare una realtà nella quale la pluralità di spiegazioni che si alternano sullo stesso fenomeno non consente quasi mai il raggiungimento di un livello di certezza di questo tenore.

Si è detto che nei contesti nei quali si "assegna al sapere scientifico naturalistico un dominio incontrastato su quello delle regole di imputazione dove "la causalità stessa divora e assorbe l'imputazione giuridica, appare "utopistico" e "paradossale" affidare l'imputazione dell'evento a leggi statistiche dotate di un coefficiente di validità prossimo al 100\%, soprattutto in un'era nella quale predomina l'incertezza cognitiva"72.

Quando, dunque, si voglia trovare una corretta risposta non si potrebbe prescindere dall'effettuare diverse scelte ricostruttive che, per l'appunto, si diversificano in modo sensibile quando ci si trovi innanzi ad condotta attiva o ad una condotta omissiva.

Se con riferimento alla condotta attiva si può ritenere che l'evento debba "essere imputato a prescindere dalla certezza o quasi che il comportamento alternativo lecito avrebbe evitato quel risultato lesivo", non così può sostenersi per il reato omissivo per il quale "pare giustificato richiedere un più elevato grado di evitabilità dell'evento mediante il comportamento alternativo lecito, tale da confinare con una ragionevole certezza" ${ }^{73}$.

Solo in questo modo è possibile "compensare le incertezze fisiologiche di una logica predittiva" conformata da regole cautelari prive di un univoco sostrato scientifico, "selezionando giudizi di evitabilità cristallizzati nel tempo, scartando ... quelli che recano in sé il dubbio circa l'effettiva efficacia impeditiva del comportamento alternativo lecito"74.

\section{PERITI E CONSULENTI TECNICI VERI ARBITRI DEL PROCESSO.}

\section{La buona scienza nel processo: linee guida dalla giurisprudenza di legittimità}

Parlare del rapporto fra scienza e rimprovero colposo implica necessariamente una attenzione particolare alla metodologia attraverso la quale il sapere epistemologico fa ingresso nel processo penale ${ }^{75}$.

La scelta del legislatore in favore di un processo improntato ai principi del rito accusatorio, nel quale la prova si forma nel contraddittorio delle parti, conferisce alle figure del consulente tecnico e del perito un ruolo assolutamente determinante per la ricostruzione del sostrato scientifico sul quale poggia la realtà fattuale oggetto della cognizione.

\footnotetext{
${ }^{72}$ DONINI, M. (2011), Europeismo giudiziario e scienza penale, Milano, p. 132 ss.

${ }^{73}$ VENEZIANI, P. (2013), Causalità della colpa e comportamento alternativo lecito, in DONINI, M. ORLANDI, R. (a cura di), Reato colposo e modelli di responsabilità, cit., p. 298.

74 VENEZIANI, P. (2013), p. 299.

75 Sul tema, di fondamentale importanza, CENTONZE, A. (2001), Scienza «spazzatura» e scienza «corrotta» nelle attestazioni e valutazioni dei consulenti tecnici nel processo penale, in Riv. it. dir. proc. pen., p. 1232; JASANOFF, S. (2001), La scienza davanti ai giudici, Milano; WILLIAMS, B. (2005), Genealogia della verità, Roma; PULITANÒ, D. (2006), Il diritto penale fra vincoli di realtà e sapere scientifico, in Riv. it. dir. proc. pen., p. 795.
} 
Il sapere veicolato dal perito e dal consulente tecnico illumina in egual modo l'ambito oggettivo e soggettivo del rimprovero, risultando per entrambi fattore imprescindibile.

Pur tuttavia, non dobbiamo nasconderci come proprio il contesto della ricostruzione del profilo oggettivo - deontico del rimprovero colposo demandi allo scienziato un compito di assoluta centralità.

Infatti, consulente tecnico e perito sono chiamati ad individuare e portare nel processo il contenuto scientifico e il relativo precipitato modale della regola cautelare, soprattutto quando essa costituisce elemento fondante di un rimprovero per colpa generica.

Inoltre, se ci si consente l'espressione, lo scienziato incaricato dal giudice o dalle parti processuali è chiamato ad illustrare il perimetro concreto dell'orizzonte degli eventi che l'indagato o l'imputato doveva e poteva prevedere ed evitare.

Alla consulenza tecnica e alla perizia è, dunque, affidata la ricostruzione dell'ordito nomologico - deontico nel quale si sviluppa la trama del fatto oggetto del processo penale.

Questo ruolo assolutamente preminente viene in parte temperato da formule linguistiche più o meno rassicuranti che vedono il giudice esercitare un ruolo di peritus peritorum essendo, almeno formalmente, demandato alla sua funzione la scelta della ricostruzione scientifica maggiormente corretta e plausibile posta alla base della decisone del caso concreto ${ }^{76}$.

Ma a ben vedere anche il giudice più scrupoloso soffre inevitabilmente delle aporie che caratterizzano la sua preparazione squisitamente giuridica ${ }^{77}$.

Delle stesse limitazioni cognitive soffrono ovviamente anche tutte le altre parti processuali.

Quindi, il solo terreno sul quale giudice, pubblico ministero ed avvocati possono interloquire insiste sulle scelte metodologiche attraverso le quali perizia e consulenza tecnica entrano nel processo ${ }^{78}$.

\footnotetext{
${ }^{76}$ BLAIOTTA, R. (1997), Il realismo di Karl Popper: un ideale di conoscenza oggettiva per il giudizio penale, cit., p. 3690.

${ }^{77}$ Non solo, ma la separazione fra scienza e diritto conduce ad una patente contraddizione: "da un lato lo statuto debole delle scienze che varcano la soglia dei processi spinge il giudice ad assumere un ruolo attivo nella selezione delle perizie, dall'altro," la complessità "esoterica” del linguaggio pone il giudice in una posizione di naturale inferiorità cognitiva”. Dal momento che ancora si ritiene di conferire alla scienza il ruolo di "dispensatrice di verità oggettive", il processo finisce per rappresentare "un luogo poco ospitale" per un modello democratico dei rapporti fra diritto e scienza. Si sostiene, infatti, che "la giustizia processuale, fondata sulla logica della decisione, appare una cornice normativa inadeguata a fronteggiare le incertezze della scienza e soddisfare gli interessi in gioco nelle dispute scientifiche”. Così FODDAI, M. A. (2017), Controversie scientifiche e controversie giuridiche, cit. p. 62.

78 Il problema del metodo evidenzia come l'ingresso della scienza nel processo sia reso ancora più difficile da dalla netta dicotomia che intercorre fra scienza empirica e scienza giuridica penalistica. Lo Dottrina sottolinea infatti come "il sapere penalistico è al fondo, nella sua essenza, un sapere valutativo, mentre quello scientifico fattuale è ... un sapere - per così dire - avalutativo”. La differenza sarebbe evidente sul piano del metodo poiché "mentre la scienza empirica si basa su di un metodo sperimentale, il sapere penalistico si basa su di un metodo che in definitiva potremmo definire argomentativo. La scienza esplicativa formula ipotesi e realizza verifiche delle ipotesi attraverso l'esperimento. La conoscenza scientifica, la spiegazione del fenomeno è il risultato di questo confronto fra ipotesi e verifica/falsificazione dell’ipotesi”. Una simile differenza non può smentire tuttavia quanto la scienza penalistica abbia necessità della scienza empirica poiché “il diritto penale moderno, ormai, non solo si confronta con la realtà, ma si avvale anche delle conoscenze scientifiche che riguardano tale realtà così
} 
Di questi assunti è portavoce la più attenta giurisprudenza di legittimità la quale, facendosi interprete della sua funzione nomofilattica, ha dettato al giudice di merito le linee guida che questi deve seguire nel complesso procedimento di valutazione della prova scientifica. Il giudice, infatti, deve "avere sensibilità per i problemi epistemologici, ma guardarli con attento distacco". Infatti, “per pronunziare delle buone sentenze non è per nulla necessario preferire l'una o l'altra tesi”. Tuttavia, è necessario fornire al giudice del merito alcune "indicazioni basilari" che nascono dall'"esperienza giudiziaria”.

Così, ci dice la Corte, dettando vere e proprie linee guida, "per valutare l'attendibilità di una teoria occorre esaminare gli studi che la sorreggono. Le basi fattuali sui quali essi sono condotti. L'ampiezza, la rigorosità, l'oggettività della ricerca. Il grado di sostegno che i fatti accordano alla tesi. La discussione critica che ha accompagnato l'elaborazione dello studio, focalizzata sia sui fatti che mettono in discussione l'ipotesi sia sulle diverse opinioni che nel corso della discussione si sono formate. L'attitudine esplicativa dell'elaborazione teorica. Ancora, rileva il grado di consenso che la tesi raccoglie nella comunità scientifica. Infine, dal punto di vista del giudice, che risolve casi ed esamina conflitti aspri, è di preminente rilievo l'identità, l'autorità indiscussa, l'indipendenza del soggetto che gestisce la ricerca, le finalità per le quali si muove"79.

Quando più sono le teorie scientifiche che entrano nel processo in modo reciprocamente escludente, tanto più il giudice dovrà utilizzare parametri di giudizio molto stringenti che lo conducono dapprima a valutare "l'affidabilità metodologica e l'integrità delle intenzioni” e poi a dover valutare se esista una teoria davvero affidabile, idonea a sorreggere la motivazione del giudice nel caso concreto. Infatti, a fondamento della decisione giurisdizionale deve essere posta "una teoria sulla quale si registra un preponderante, condiviso consenso" 80 .

Dal momento che il giudice di merito non dispone delle conoscenze e delle competenze sufficienti, le teorie scientifiche, anche contrapposte, debbono essere portate nel processo dagli esperti i quali sono chiamati a delineare lo scenario degli studi ed a fornire gli elementi di giudizio che consentano al giudice di comprendere se, ponderate le diverse rappresentazioni scientifiche del problema, possa pervenirsi ad una "metateoria" in grado di guidare affidabilmente l'indagine. Di tale complessa indagine il giudice è infine chiamato a dar conto in motivazione, esplicitando le informazioni

BARTOLI, R. (2018), Diritto penale e prova scientifica in CANZIO, G.- LUPARIA, L. (a cura di), Prova scientifica e processo penale, cit., p. 82.

${ }^{79}$ Per questo la sentenza afferma come sia "ovvio che, in tema di amianto, un conto è un'indagine condotta da un organismo pubblico, istituzionale, realmente indipendente; ed altra cosa è un'indagine commissionata o gestita da soggetti coinvolti nelle dispute giuridiche”.

${ }^{80}$ Peraltro, come sottolinea la Dottrina, "quando il perito o il consulente tecnico entrano nelle aule giudiziarie devono conformarsi alle regole procedimentali e abbandonare, laddove incompatibili, le proprie categorie. Vi sono valori fra i quali la certezza del diritto, il divieto di non liquet e il principio di legalità che sono estranei allo scienziato ma che reggono il processo e che non possono perciò essere disattesi. La funzione cognitiva non si estende fino a ricomprendere tra i fini processuali l'elaborazione di una teoria infallibile secondo lo statuto dello scienziato perché l'accertamento di un accadimento del passato penalmente rilevante, può avvenire esclusivamente secondo le categorie del codice di procedura penale e la risposta deve essere sempre e solo normativa". Così CECCHI, M. (2017), L'”autonoma valutazione" del giudice quale baluardo contro l'appiattimento sulla prova scientifica, in Dir. pen. proc., p. 915. 
scientifiche disponibili e fornendo razionale spiegazione, in modo completo e comprensibile a tutti, dell'apprezzamento compiuto ${ }^{81}$.

Lo stesso Consigliere Relatore della sentenza Cozzini fino ad ora richiamata, pochi anni dopo ha voluto trasporre questi concetti, nati sul difficile terreno delle malattie professionali, anche nel non meno impervio terreno della colpa medica, caratterizzato dalla presenza di linee guida e protocolli accreditati dalla comunità scientifica internazionale.

Qui si afferma, infatti, che "l'itinerario per il conseguimento della scientificità del giudizio”, non sempre appare lineare ${ }^{82}$.

Ne discende come, "per valutare l'attendibilità di una tesi occorra esaminare gli studi che la sorreggono; l'ampiezza, la rigorosità, l'oggettività delle ricerche; il grado di consenso che l'elaborazione teorica raccoglie nella comunità scientifica”. Unitamente a tali criteri deve essere conferito un primario rilievo all'"identità, l'autorità indiscussa, l'indipendenza del soggetto che gestisce la ricerca, le finalità per le quali si muove”.

Queste linee guida rendono possibile, in una certa misura, l'ingresso nel processo penale alla sola buona scienza. Infatti, il giudice, si dice, dopo aver ponderato l'affidabilità e l'integrità delle tesi, deve valutare se esista una teoria in grado di fornire concrete, significative ed attendibili informazioni idonee a sorreggere la motivazione ${ }^{83}$.

Il quadro prasseologico evidenziato riserva al giudice un quanto mai difficile ruolo di peritus peritorum che, lungi dal costituire elemento sintomatico "di potere e di supremazia" rappresenta "piuttosto, l'indicazione di un metodo" ${ }^{84}$.

Naturalmente tutti questi assunti sono posti a baluardo dei superiori principi di legalità, di determinatezza e di colpevolezza. Infatti, ci dice la Corte, ciò significa "che l'ontologica 'terzietà' del sapere scientifico accreditato è lo strumento a disposizione del

\footnotetext{
${ }^{81}$ Tutte queste affermazioni sono tratte dalla sentenza Cass. pen., Sez. IV, 13 dicembre 2010, n. 43786, in DeJure.

${ }^{82}$ Cass. Pen. sez. IV, 9 aprile 2013, n. 16237, Rel Blaiotta, Imp. Cantore, in DeJure. Infatti, "l'acquisizione al processo di informazioni scientifiche adeguatamente attendibili non è sempre agevole, tanto più quando si entra in ambiti complessi, controversi, caratterizzati da sapere in divenire. Tale situazione rende chiaro che il giudice non può certamente assumere un ruolo passivo di fronte allo scenario del sapere scientifico, ma deve svolgere un penetrante ruolo critico, divenendo (come è stato suggestivamente affermato) custode del metodo scientifico".

Così, "il primo e più indiscusso strumento per determinare il grado di affidabilità delle informazioni scientifiche che vengono utilizzate nel processo è costituto dall'apprezzamento in ordine alla qualificazione professionale ed all'indipendenza di giudizio dell'esperto". Ma questo potrebbe non essere sufficiente. Infatti, ci dice la Corte, "non si tratta tanto di comprendere quale sia il pur qualificato punto di vista del singolo studioso, quanto piuttosto di definire, ben più ampiamente, quale sia lo stato complessivo delle conoscenze accreditate".

${ }^{83}$ La Corte sottolinea come "si tratta di indagine afferente alla sfera del fatto e dunque rimessa alla valutazione del giudice di merito; mentre il controllo di legittimità attiene solo alla razionalità ed alla rigorosità dell'apprezzamento compiuto".

${ }^{84}$ Critica l'idea di un giudice peritus peritorum TONINI, P. (2015), Nullum iudicium sine scientia, cit. p. 1413 secondo il quale proprio Cass. pen. sez. V, 7 settembre 2015, n. 1105, "ha rigettato tacciandola come "obsoleta" la concezione del giudice peritus peritorum ed ha affermato che il magistrato deve valutare il responso dell'esperto sulla base di quei criteri che noi sappiamo essere quelli della sentenza Cozzini e che la S.C. ha riepilogato nel modo seguente. Il giudice deve valutare l'attendibilità soggettiva dell'esperto, la scientificità del metodo adoprato, il margine di errore accettabile e l'attendibilità di un risultato "secondo un metodo di approccio critico non dissimile, concettualmente, da quello richiesto per l'apprezzamento delle prove ordinarie””.
} 
giudice e della parti per conferire oggettività e concretezza al precetto ed al giudizio di rimprovero personale" 85 .

I pregevolissimi sforzi della giurisprudenza, profusi non a caso in contesti di responsabilità colposa, non esauriscono la problematica dell'ingresso della buona scienza nel processo.

Il tema richiede piuttosto di effettuare la distinzione fra un novero di problematiche che accomunano tutti gli ambiti nei quali la risposta epistemologica permea la declinazione processuale del diritto penale, rispetto alle questioni proprie e peculiari del rimprovero colposo.

\section{Ma i problemi rimangono: affidabilità e imparzialità degli scienziati nel processo penale}

Muovendo da un piano più generale, è appena il caso di ricordare come da più parti si sottolinei il rischio di una eccessiva fidelizzazione del consulente e del perito rispetto all'autorità pubblica che gli conferisce l'incarico ${ }^{86}$. La circostanza potrebbe avere significativi e diversi precipitati, incidendo in primo luogo sull'indipendenza di chi accetti l'incarico, il quale potrebbe sentirsi gravato da una sorta di obbligo di risultato in ordine alla risposta offerta.

Specularmente, è ben possibile che chi sceglie quel consulente o quel perito lo faccia proprio perché sa che egli è latore di una certa ricostruzione funzionale alla tesi che si desidera sostenere.

Se queste circostanze si verificano ed appaiono, almeno astrattamente, più comprensibili con riferimento all'incarico conferito dall'avvocato dell'imputato o della parte civile, non possono però tollerarsi quando costituiscono il presupposto operativo di scelte effettuate dal pubblico ministero o dal giudice ${ }^{87}$.

È peraltro noto come l'affidabilità e l'imparzialità delle informazioni scientifiche che entrano nel processo non sia presidiata da un adeguata risposta penalistica.

Ad un simile problema si è risposto ipotizzando l'estensione al consulente tecnico dell'obbligo di prestare la dichiarazione di impegno di cui all'art. 497 c.p.p., ma neppure questa soluzione sembra decisiva.

Certo è che accanto ad un ripensamento del contenuto della consulenza e della perizia e del rapporto fra giudice e perito, non può mancare un presidio penalistico alle dichiarazioni infedeli portate nel processo da consulenti e periti.

Negata da dottrina e giurisprudenza l'applicabilità della fattispecie della falsa perizia (art. 373 c.p.) al consulente tecnico, si è ipotizzata in questo caso l'operatività della falsa testimonianza sul presupposto che, anche in altri contesti, (ad es. nell'art. 468 c.p.p.) il temine "testimone" è utilizzato in senso a-tecnico. Il consulente risponderebbe, allora, del reato di falsa testimonianza quando presenti una consulenza che dia conto

\footnotetext{
${ }^{85}$ Proprio per questo motivo la sentenza ci ricorda che "Tale ordine di idee trova puntuale applicazione nell'ambito di cui ci si occupa: il legislatore ha evidentemente colto l'importanza del sapere scientifico e tecnologico consolidatosi in forma agevolmente disponibile in ambito applicativo ed ha al contempo richiesto il sicuro, condiviso accreditamento delle direttive codificate”.

${ }^{86}$ Le prescrizioni codicistiche in ordine ai criteri di scelta del perito e del consulente tecnico sono contenute negli artt. 221 e 225 c.p.p.

87 PIERGALLINI, C. (2007), La regola dell'oltre ogni ragionevole dubbio al banco di prova di un ordinamento di civil law, in Riv. it. dir. proc. pen., p. 599.
} 
solo parzialmente delle conoscenze scientifiche sul punto, o elabori teorie ad hoc, che non trovano riscontro nella comunità scientifica ${ }^{88}$.

Altri autori hanno infine suggerito di ricondurre la condotta di falsa consulenza nell'alveo degli artt. 374, 374 bis e 380 c.p. nei casi nei quali il consulente sia esaminato tanto in dibattimento, quanto nel corso delle indagini preliminari. Si tratta anche in questo caso di una tutela molto frammentaria, che non elude il problema centrale della mancanza di un presidio sanzionatorio rispetto ad obblighi di verità che dovrebbero essere riconosciuti anche in capo al consulente tecnico.

Le aporie normative finiscono per incidere in modo determinante sull'effettività riconosciuta al garantismo penale, il quale deve assolutamente poggiarsi su un "paradigma epistemologico" che orienti in modo certo la coscienza e la conoscenza del giudice ${ }^{89}$.

\section{3. (Segue) I problemi del rimprovero colposo (e qualche soluzione)}

Questi profili problematici si acuiscono nell'incontro fra scienza e colpa.

Senza giungere al livello di gravità che certe vicende giudiziarie ci ricordano, è appena il caso di ricordare come il rapporto fra sapere scientifico e rimprovero colposo costituisca terreno di elezione per lo sviluppo di alcune problematiche peculiari che in questa sede possiamo solo ricordare in modo rapsodico ${ }^{90}$.

Muovendo dall'analisi della giurisprudenza sui danni lungolatenti da utilizzo industriale dell'amianto, possiamo evidenziare come la determinazione dello spettro cautelare della regola di condotta non osservata sia stato sovente tracciato sulla base delle acquisizioni scientifiche maturate in un momento successivo, ovvero quello nel quale si stava celebrando il processo.

Come insegnano, fra le molte, la sentenza di Appello e di Cassazione sul Petrochimico di Porto Marghera, la determinazione della prevedibilità dell'evento, che

88 Di particolare importanza Tribunale Milano, 20 dicembre 1999, Montingelli, con nota di MUCCIARELLI, F. (2000), Colpa e causalità: una sentenza contro il brocardo «qui in re illicita versatur, tenetur etiam pro casu», in Foro Ambrosiano. La sentenza, infatti, non ritiene sufficiente "come dato idoneo a fungere da parametro per l'adeguamento della condotta dell'agente un'informazione scientifica pur accreditata, quando la stessa sia o isolata ... ovvero sia ancora limitata nella sua circolazione al mondo strettamente scientifico".

89 PULITANÒ, D. (2006), Il diritto penale fra vincoli di realtà e sapere scientifico, in Riv. it. dir. proc. pen., p. 795. Di centrale importanza quanto ricordato dalla Dottrina secondo la quale, in commento Cass. pen. sez. V, 7 settembre 2015, n. 1105 ritiene che "non vale più il principio dell’ipse dixit, secondo cui tutto quello che ha affermato lo scienziato deve dirsi entrato automaticamente nel processo penale. Per aver ingresso nel processo, il dato deve essere "scientifico" e cioè deve avere i requisiti della prova di cui all’art. 192, comma 2, c.p.p.”. Così TONINI, P. (2015), Nullum iudicium sine scientia, cit, p. 1415.

90 Tribunale penale di L’Aquila, Giudice dott. Billi, n. 380 del 2013 in www.penalecontemporaneo.it. La Corte d'Appello di L'Aquila, con sentenza del 10 novembre 2014, n. 3317 in www.penalecontemporaneo.it, ha riformato la pronuncia di primo grado mandando assolti i sei membri della Commissione Grandi Rischi e riducendo la pena a due anni per l'ex vice capo del settore tecnico della Protezione Civile. La sentenza pronunciata dalla Corte d'Appello è stata confermata da Cass. pen. Sez. IV, 24 marzo 2016, n. 12478, in DeJure e se ci si consente con commento di VALBONESI, C. (2016), Terremoti colposi e terremoto della colpa. riflessioni a margine della sentenza "grandi rischi", in Riv. it. dir. proc. pen., 2016, p. 1496. Per la letteratura scientifica si veda, ex plurimis, AMATO, A. GALADINI, F. (2013), Gli argomenti della scienza nel processo dell'Aquila alla "Commissione Grandi Rischi”, in Rivista di cultura e politica scientifica, p. 7 ss. e AMATO, A. -CERASE, A. - GALADINI, F. (2015), Terremoti, comunicazione, diritto. Riflessioni sul processo alla "Commissione Grandi Rischi", Roma. 
l'osservanza della regola cautelare mirava a scongiurare, muta con il mutare delle risultanze scientifiche in ordine alla correlazione fra uso dell'amianto e insorgenza del mesotelioma pleurico. Non vi sono dubbi, infatti, che al momento nel quale gli imputati rivestivano i rispettivi ruoli apicali e di garanzia all'interno dell'azienda fosse nota la sola correlazione fra amianto e la patologia non mortale dell'asbestosi. Ma il dovere di tutelare la salute del lavoratore, quale clausola elastica ed interminata che, secondo la giurisprudenza fonderebbe lo spettro cautelare del precetto, consente di modificare l'orizzonte della prevedibilità dell'evento fino ad estenderlo anche a patologie mortali non preconizzabili negli anni '70 del secolo scorso ${ }^{91}$.

La distorsione dei paradigmi fondativi del rimprovero colposo, che a ben vedere ha riguardato anche il profilo dell'evitabilità dell'evento, affidata alla cautela di contenuto astensionistico, espressione della default option di matrice precauzionale, è stata possibile grazie alla forzatura del sostrato scientifico e dunque nomologico della regola cautelare.

Da queste storture occorre tenere davvero ben distinti i casi nei quali, sempre in tema di rimprovero colposo, il consulente tecnico o il perito sono chiamati a portare nel processo penale la scienza del senno di poi in una diversa funzione, in questo caso favorevole al reo. Se la regola scientifica colora di tipicità il rimprovero colposo attraverso la sua incarnazione in regola di diligenza, allora non pare utopistico demandare al consulente tecnico o al perito il compito di evidenziare come la regola (scritta) applicata al caso concreto dall'imputato risulti ex post, al momento del processo, una regola inefficace alla luce della miglior scienza ed esperienza del momento storico ${ }^{92}$.

Pertanto, il compito di denunziare l'inutilità, conosciuta ex post, dell'osservanza di una regola che non è mai stata efficace spetta allo scienziato chiamato a fornire il suo obiettivo apporto nel processo. Si pensi al medico tratto a giudizio per la morte di un paziente cagionata dalla scorretta effettuazione di una manovra chirurgica. Al momento del processo la scienza risulta concorde nel dire che quella manovra non avrebbe avuto il contenuto salvifico che le era invece attribuito nel momento in cui fu commesso il fatto.

Lo scienziato deve farsi portavoce della circostanza che inficia il capo di imputazione colposo per assenza di un comportamento alternativo lecito efficacemente esperibile dalla parte.

Il volto ancipite della perizia e della consulenza tecnica origina, senza dubbio, dalla compresenza di diverse tesi scientifiche che in una dimensione sincronica si contendono il campo delle scelte maggiormente determinanti, trasfuse in regole cautelari che sovente divengono nient'altro che dei parametri convenzionali sui quali modellare il dovere di diligenza.

\footnotetext{
${ }^{91}$ Per questo inquietante passaggio si legga Cass. pen. sez. IV, 17 maggio 2006, n. 4675, Imp. Bartalini, in DeJure, nella sezione che si occupa dell'elemento soggettivo ed in particolare della prevedibilità dell'evento.

92 Questo potrebbe accadere in tema di linee guida e protocolli medici. Ad esempio, potrebbe verificarsi la circostanza secondo la quale l'omicidio colposo del paziente si sia consumato in costanza di una regola cautelare (sub specie di linea guida o di protocollo) che in un momento successivo viene riconosciuta dalla comunità internazionale come inidonea a scongiurare l'evento morte che si è verificato e per il quale il medico è soggetto ad un procedimento penale. In questo caso il consulente tecnico o il perito devono rappresentare al PM o al Giudice il mutamento della cautela che dimostra l'assenza di responsabilità colposa dell'imputato.
} 
Per evitare, dunque, che periti e consulenti tecnici siano portatori di un quadro epistemologico fallace è possibile e necessario attuare una pluralità di strumenti di contrasto quali: a) il riconoscimento di una centralità assoluta agli obblighi di motivazione del giudice; b) il sostegno al processo legislativo che sta a poco a poco conducendo alla valorizzazione delle linee guida e dei protocolli sul modello tracciato dall'art. 5 della L. 24 del 2017 (come veicolati ai sensi dell'art. 15 della Legge).

Le risultanze del dibattito scientifico che si consuma in seno al processo e che, a ben vedere, si incentra sulla scientificità del metodo utilizzato e sull'attualità dello stesso, debbono essere trasfuse nella motivazione della sentenza, luogo deputato alla spiegazione delle valutazioni tecnico - scientifiche effettuate nel processo. In tale contesto il giudice dovrà dimostrare non solo l'autorevolezza e la plausibilità della soluzione peritale ritenuta valida, ma altresì il grado di accettazione degli enunciati proposti nella comunità scientifica di riferimento.

In questo compito il giudice è sicuramente coadiuvato dai principi espressi nella sentenza Daubert quali impongono che, pur nella condizione di volubilità della regola scientifica applicata, la motivazione delle sentenze debba divenire "sofisticata"93 e debba dar conto del grado di affidabilità della regola scientifica, basato sulla c.d. "teoria della conferma”. Così, "quando la conferma non è forte, il giudizio deve essere di inaffidabilità; e quando la conferma potrebbe essere forte, ma è smentita da un solo controesempio, il giudizio deve essere egualmente di inaffidabilità”. Solo seguendo questo indirizzo la "scienza spazzatura" può rimanere fuori dal processo penale ${ }^{94}$.

L'accezione di un giudice quale peritus peritorum risiede proprio in questa sua funzione di «custode e garante della scientificità della conoscenza fattuale espressa dal processo» ${ }^{95}$. Si tratta, senza dubbio, di un giudizio sul fatto rimesso ai giudici di merito e non certo al giudice di legittimità che può solo entrare nel merito della correttezza metodologica adottata dal giudice di primo e secondo grado ${ }^{96}$.

Infine, come avremo modo di approfondire, il fertile terreno di riflessione sviluppatosi intorno alla responsabilità medica restituisce un complesso normativo nel quale si conferisce un ruolo precipuo alle cautele che nascono dalla prassi e vengono codificate dai più autorevoli organismi internazionali.

L'esempio più fulgido risiede nella previsione legislativa frutto del combinato disposto fra art. 5 e art. 15 della L. 24 del $2017^{97}$ il quale, ove vi fosse la volontà politica di compiere un simile passo, potrebbe essere esteso agli operatori del rischio della protezione civile ${ }^{98}$.

\footnotetext{
93 STELLA F. (2002), Giustizia e modernità, cit., p. 462.

94 STELLA F. (2002), p. 463.

95 Pur coni limiti che abbiamo evidenziato, per tutti TONINI, P. (2015), Nullum iudicium sine scientia. Cadono vecchi idoli nel caso Meredith Kercher, cit. p. 1411.

${ }^{96}$ Cass. pen., Sez. IV, 13 dicembre 2010, n. 43786, cit.

${ }^{97}$ L'art. 15, rubricato Nomina dei consulenti tecnici d'ufficio e dei periti nei giudizi di responsabilità sanitaria, che "Nei procedimenti civili e nei procedimenti penali aventi ad oggetto la responsabilità sanitaria, l'autorità giudiziaria affida l'espletamento della consulenza tecnica e della perizia a un medico specializzato in medicina legale e a uno o più specialisti nella disciplina che abbiano specifica e pratica conoscenza di quanto oggetto del procedimento, avendo cura che i soggetti da nominare, scelti tra gli iscritti negli albi di cui ai commi 2 e 3, non siano in posizione di conflitto di interessi nello specifico procedimento o in altri connessi e che i consulenti tecnici d'ufficio da nominare nell'ambito del procedimento di cui all'articolo 8, comma 1, siano in possesso di adeguate e comprovate competenze nell'ambito della conciliazione acquisite anche mediante specifici percorsi formativi”.

${ }^{98}$ Senza per forza prevedere uno statuto peculiare della responsabilità colposa sul modello dell'art. 590 sexies c.p., ma recuperando, invia interpretativa i criteri di giudizio offerti dall’art. 2236 c.p.
} 
Ci si conceda una ulteriore e breve considerazione finale. In quest'epoca nella quale l'affidabilità di uno scienziato è spesso misurata dai consensi che questi matura in relazione al proprio profilo declinato sui diversi social network, in quest'epoca nella quale si confonde spesso l'etica della divulgazione con la ricerca della fama personale che conduce alla creazione di una scienza spettacolo dominata dalla figura dello scienziato star, una forte speranza deve essere riposta nella capacità degli ordini professionali di selezonare le figure maggiormente idonee a rappresentare nel processo i saperi dei quali essi si fanno esponenti.

La predisposizione di appositi albi dai quali il giudice, il consulente tecnico e il difensore possano mutuare l' indicazione di esperti qualificati, unitamente alla previsione di sanzioni disciplinari, anche di natura interdittiva, costituisce quel complesso di misure minime atte a scongiurare il dilagare di prassi processuali che affidano al canone della persuasione linguistica la spiegazione scientifica dei fenomeni oggetto della cognizione giurisdizionale.

\section{IL QUESITO RIVOLTO AL PERITO E AL CONSULENTE TECNICO IN TEMA DI REATO COLPOSO}

Fra i numerosi precipitati della sempre più intollerabile duttilità del rimprovero colposo, deve annoverarsi il problema "delle forme e dei tempi di contestazione" dello stesso ${ }^{99}$.

Infatti, la contestazione del crimen culposum si presenta spesso del tutto indeterminata (soprattutto nel caso della colpa generica) e "finisce per coprire tutto l'universo cautelare, generico e specifico", richiamando "tutte le norme a contenuto preventivo che in abstracto si rivelino idonee ad essere applicate nel caso concreto" ${ }^{100}$.

Se è pur vero che il deficit di normatività che affligge il crimen culposum e l'altissimo grado di complessità tecnico scientifica che lo connota non consentono una corretta conoscenza della regola cautelare esattamente violata se non all'esito, quanto meno, delle indagini affidate ai consulenti tecnici, tuttavia una imputazione vaga si trasforma in una "incolpazione sbilanciata sull'evento (quando presente nella struttura del reato) e sul nesso di causalità naturalistico" ${ }^{101}$.

Dunque, se la formulazione dell'accusa si presenta così indeterminata e fluida, sarà possibile non solo adattarla a "qualunque sillogismo decisorio", ma si riscontreranno gravi difficoltà nella valutazione ex post della decisione giudiziale ${ }^{102}$.

Accade inoltre sovente che il capo di imputazione consideri quali regole cautelari non osservate e pertanto quali elementi fondativi della colpa, precetti istitutivi di posizioni di garanzia.

Come se ciò non bastasse, un capo di imputazione così formulato può subire, durante il processo, modifiche sostanziali che ne stravolgono il volto iniziale, con buona pace del diritto di difesa sancito dall'art. 24 Cost.

\footnotetext{
${ }^{99}$ CASTRONUOVO, D. (2002), La contestazione del fatto colposo: discrasie tra formule prasseologiche d'imputazione e concezioni teoriche della colpa, in Cass. pen., p. 3836; MUSCO, E. (1971), La contestazione dei reati colposi, in Riv. it. dir. proc. pen., p. 330.

${ }^{100}$ CASTRONUOVO, D. (2002), p. 3837.

101 CASTRONUOVO, D. (2002), p. 3842. Di centrale importanza sul tema VARRASO, G. (1999), Omessa o insufficiente descrizione dell'imputazione, nullità della vocatio in iudicium e autorità competente alla rinnovazione, in Riv. it. dir. proc. pen., p. 339.

${ }^{102}$ CASTRONUOVO, D. (2002),cit., p. 3843.
} 
Infatti, la giurisprudenza in tema di formulazione e di modifica della imputazione del reato colposo ritiene che "le variazioni del grado e del tipo di colpa debbano sempre considerarsi irrilevanti, ai fini dell'inosservanza del principio di correlazione tra accusa e sentenza" ${ }^{103}$. In questo senso, "le modifiche attinenti alla colpa non devono essere considerate quali ipotesi di mutamento del fatto, e per questa ragione rimangono saldamente nelle mani del giudice che può disporne a piacimento"104.

Si è più volte ripetuto come "nei reati colposi, la sostituzione o l'aggiunta di un particolare profilo di colpa, sia pure specifica, al profilo di colpa originariamente contestato, non vale a realizzare diversità o immutazione del fatto ai fini dell'obbligo di contestazione suppletiva di cui all'art. 516 c.p.p. e dell'eventuale ravvisabilità, in carenza di valida contestazione del difetto di correlazione tra imputazione e sentenza ai sensi dell'art. 521 c.p.p.”. Infatti, "nei procedimenti per i reati colposi, quando nel capo di imputazione siano stati contestati elementi generici e specifici di colpa, non sussiste violazione del principio di correlazione fra sentenza e accusa mossa nel caso in cui il giudice abbia affermato la responsabilità del prevenuto per un'ipotesi di colpa diversa da quella di colpa specifica contestata ma rientrante in quella di colpa generica. Infatti, il riferimento alla colpa generica, anche se seguito dall'indicazione di un determinato, specifico profilo di colpa, evidenzia che la contestazione riguarda la condotta dell'imputato globalmente considerata, sicché questi è in grado di difendersi relativamente a tutti gli aspetti del comportamento tenuto in occasione dell'evento di cui è chiamato a rispondere, indipendentemente dalla specifica norma che si intende violata” ${ }^{105}$.

Questi assunti, lungi dall'essere frutto di approdi recenti, rappresentano un comune sentire maturato negli anni ed anzi sono oggetto di una certa qual continenza da parte della Suprema Corte la quale riconosce oggi la libertà assoluta del giudice di decidere il profilo di colpa da privilegiare nei soli casi nei quali si contesti la colpa generica $^{106}$.

Come abbiamo sottolineato, la specificità del rimprovero colposo insiste nella sussistenza di una specifica modalità di condotta che si sostanza in una regola cautelare. Quando quest'ultima si cristallizza in una regola di condotta predeterminata, dando luogo alla colpa specifica, il mutamento del capo di imputazione "modifica un aspetto rilevante del fatto storico, ragion per cui occorrerebbe dare applicazione, in simile evenienza, all'art. 516 c.p.p." ${ }^{107}$.

Purtroppo, però, una simile soluzione non pare esperibile poiché la giurisprudenza in tema di colpa pretende che, affinché il mutamento che si verifica possa essere ritenuto rilevante ai sensi dell'art. 516 c.p.p., esso comporti "una trasformazione radicale di tutti gli elementi essenziali dell'oggetto del processo". ${ }^{108}$

\footnotetext{
${ }^{103}$ CAIANIELLO, M. (2013), Imputazione e garanzie: la contestazione e la qualificazione del fatto nel reato colposo, in DONINI, M. - ORLANDI, R. (a cura di), Reato colposo e modelli di responsabilità, Bologna, p. 241.

104 CAIANIELLO, M. (2013), cit. p. 243.

105 Cass. pen. sez. IV, 19 maggio 2009, n. 31968, Imp. Raso, in CED Rv. 245313.

106 Cass. pen. sez. IV, 19 maggio 2009, n. 31968, cit.

107 CAIANIELLO, M. (2013), Imputazione e garanzie: la contestazione e la qualificazione del fatto nel reato colposo, cit. p. 346; sull'identità del fatto si veda per tutti, CORDERO, F. (1958), Considerazioni sul principio di identità del “fatto”, in Riv. it. dir. proc. pen., p. 940.

${ }^{108}$ CAIANIELLO, M. (2013), p.535.
} 
Così, il fatto nuovo viene ricondotto nella diversa e meno garantista disciplina dell'art. 518 c.p.p. ${ }^{109}$

La speranza, anche in questo caso, è riposta in un sempre maggiore sforzo di tipizzazione del rimprovero colposo che, riducendo l'ambito applicativo della colpa generica, almeno nel settore della prevenzione del rischio consentito, permetta l'ingresso nel processo di solide, determinate e puntuali regole cautelari sulla base delle quali tanto potrà difendersi l'imputato quanto dovrà decidere il giudice ${ }^{110}$.

\section{IL FUTURO DEI RAPPORTI FRA DIRITTO E SCIENZA: SOLUZIONI POSSIBILI DI UNA SINERGIA SEMPRE PIÙ IRRINUNCIABILE}

Le molteplici difficoltà che caratterizzano l'incontro fra scienza e diritto non inficiano un dato di realtà che si radica sulla sostanziale irrinunciabilità di questa sinergia.

Non essendo più possibile porre in discussione l'an del contributo scientifico nella determinazione delle responsabilità penali è tuttavia possibile riflettere in una prospettiva construens sul quomodo dell'epistemologia giuridica.

Questo processo di indagine, volto alla ricerca di possibili paradigmi sostanziali e procedurali in virtù dei quali sia possibile garantire che la miglior scienza ed esperienza del momento storico diventi la vera protagonista della decisone giudiziaria, si snoda attraverso valutazioni che coinvolgono profili solo apparentemente eterogenei.

Il primo di essi insiste su quel necessario recupero di tipicità del rimprovero colposo invocato, ormai da molti anni, dalla dottrina più attenta, la quale sottolinea come la regola cautelare debba rappresentare ancor prima che una regola di giudizio nelle mani del giudice, una regola di condotta "nelle mani del cittadino"111.

L'auspicio sembra essere stato raccolto dal legislatore il quale, intervenendo a più riprese sul delicato terreno della responsabilità del sanitario, ha valorizzato il ruolo delle linee guida e dei protocolli quali discipline idonee ad integrare il rimprovero colposo.

Se già con la Legge Balduzzi si era addivenuti a valorizzare il precipuo ruolo delle linee guida e dei protocolli nell'ambito della responsabilità medica, è certamente con la Legge Gelli Bianco che tali fonti assurgono a profilo integratore del precetto colposo $^{112}$.

109 CAIANIELLO, M. (2013), p. 535. Il tema di ricerca non può prescindere da CARNELUTTI, F. (1946), Saggio di una teoria integrale dell'azione, in Riv. dir. proc. civ., p. 17.

110 Anche recentemente la Suprema Corte ha confermato che la mancata corrispondenza fra l'addebito di colpa specifica mosso ad un datore di lavoro e il riconoscimento di una colpa generica come fondamento della sentenza di condanna non costituisca violazione degli artt. 516, 518 e 522 c.p.p. perché "in definitiva, al datore di lavoro è stato correttamente addebitato - sulla scorta di quanto contestato in fatto di non aver valutato adeguatamente dove si stava svolgendo l'attività lavorativa...”. Così Cass. pen. sez. IV, 17 gennaio 2019, n. 14270 in DeJure.

111 Per questa conclusione GIUNTA, F. (2008), La legalità della colpa, in Criminalia, p.151. Si veda inoltre, MARINI, G. (1994), «Rischio consentito» e tipicità della condotta. Riflessioni, in Scritti in memoria di Renato Dell'Andro, Bari, p. 560; PIOLETTI, U. (1990), Contributo allo studio del delitto colposo, Padova; MICHELETTI, D. (2000), La colpa nella bancarotta semplice patrimoniale. Contributo allo studio del la regola cautelare come criterio di delimitazione della tipicità colposa, in Riv. trim. dir. pen. econ., p. 609.

${ }^{112}$ Con esclusivo riferimento agli aspetti penalistici della legge Gelli Bianco, ex multis, CENTONZE, F. CAPUTO, M. (2016), La risposta penale alla malpractice: il dedalo di interpretazioni disegnato dalla 
Le linee guida e protocolli, ove dotati di quel contenuto modale che traccia il percorso impeditivo dell'evento, sono suscettibili di assurgere a rango di regole cautelari dotate di una validità epistemica rafforzata, proprio in ragione dell'autorevolezza dell'organo che le riconosce e le emana ${ }^{113}$.

Sebbene non si possano ignorare i problemi legati all'eventuale obsolescenza della cautela e alle incertezze applicative che nascono dalla molteplicità delle diverse regole che insistono su certe discipline, pur tuttavia la codificazione delle regole modali attraverso le quali si può gestire il rischio e la scelta preventiva degli organismi maggiormente accreditati ad esprimerla, rafforzano il precetto cautelare dotandolo di un corredo scientifico che altrimenti potrebbe risultare deficitario. Questo processo di codifica, scelta, riorganizzazione e diffusione di regole cautelari espressione di un solido precipitato scientifico deve essere intrapreso per tutti i settori della gestione del rischio, indipendentemente dal fatto che si voglia o meno estendere agli altri operatori il vantaggio che la disposizione dell'art. 590 quater riserva agli esercenti un servizio sanitario.

In questo senso anche le aperture giurisprudenziali appaiono di sicura pregevolezza e di continua evoluzione.

In particolare, all'indomani dell'entrata in vigore della Legge Balduzzi, l'illustre relatore della Sentenza Cantore, statuiva come le linee guida costituissero "sapere scientifico e tecnologico codificato, metabolizzato, reso disponibile in forma condensata, in modo che possa costituire un'utile guida per orientare agevolmente, in modo efficiente ed appropriato le decisioni terapeutiche.” Queste regole "non danno luogo a norme propriamente cautelari e non configurano, quindi, ipotesi di colpa specifica. Esse, tuttavia, hanno a che fare con le forti istanze di determinatezza che permeano la sfera del diritto penale”. La necessità di eterointegrare il precetto colposo costituisce “l'antidoto più forte contro l'imponderabile soggettivismo del giudice, ed è

riforma Gelli-Bianco, in Riv. it. med. leg., p. 1361; AMATO, G. (2017), Professionisti “salvi” se l'evento dannoso è dovuto a imperizia, in Guida dir., n. 15, p. 51; BRUSCO, C. (2017), La nuova legge sulla responsabilità professionale degli esercenti le professioni sanitarie, in www.ilpenalista.it, 1 marzo 2017, [consultato il 13 giugno 2019]; ID. (2017), La colpa penale e civile, Milano,, spec. p. 233; CAPUTO, M. (2017), La responsabilità penale dell'esercente la professione sanitaria dopo la L. n. 24 del 2017 ... "quo vadit”"? Primi dubbi, prime risposte, secondi dubbi, in Danno e responsabilità, p. 293; ID. (2017), I nuovi limiti della sanzione penale, in LOVO, M.- NOCCO L. (a cura di), La nuova responsabilità sanitaria. Le novità introdotte dalla Legge Gelli, Milano, p. 26; ID, Colpa penale del medico e sicurezza delle cure, Torino, 2017; DE FRANCESCO, G. (2017), In tema di dovere terapeutico, colpa medica e recenti riforme, in www.lalegislazionepenale.eu, 2 maggio 2017, [consultato il 13 giugno 2019]; DE LIA, A. (2017), La "colpa medica”: dal tramonto del modello "Balduzzi” all'alba di un nuovo sistema. Brevi note su di una riforma in stile "pulp", in www.archiviopenale.it, 27 giugno 2017. [consultato il 13 giugno 2019]; ISOLABELLA, L.- QUADRARO, A. (2017), Così l'osservanza delle pratiche cliniche diventa tassativa, in Guida dir., n. 15, p. 56 e ss.; PALMA, M. (2017), Molto rumore per nulla: la legge GelliBianco di riforma della responsabilità penale del medico, in Riv. it. med. leg., p. 523; RISICATO, L. (2017), Il nuovo statuto penale della colpa medica: un discutibile progresso nella valutazione della responsabilità del personale sanitario, in www.lalegislazionepenale.eu, 5 giugno 2017, [consultato il 13 giugno 2019].

113 GIUNTA, F. (2013), Protocolli medici e colpa penale secondo il "Decreto Balduzzi", in Riv. it. med. leg., p. 819; BRUSCO, C. (2017), Cassazione e responsabilità del medico. Tipicità e determinatezza del nuovo art. 590 sexies c.p., in Dir. pen. cont., p. 211. Di vivo interesse, sulle linee guida, TORRE, V. (2016), Linee guida e tassatività, in AA.VV. (a cura di) Scritti in onore di Luigi Stortoni, Bologna, p. 309 e TERROSI VAGNOLI, E. (1999), Le linee guida per la pratica clinica: valenze e problemi medico legali, in Riv. it. med. leg., p. 189. 
quindi garanzia di legalità, imparzialità prevedibilità delle valutazioni giuridiche"114. L'idea che le linee guida non "siano in grado di offrire standard legali precostituiti" dipende dal loro "diverso grado di affidabilità, diverse finalità specifiche, metodologie variegate e vario grado di tempestivo adeguamento al sapere scientifico" ${ }^{115}$.

In particolare, la sentenza, pronunciandosi in un quadro legislativo ancora non puntuale come quello offerto in anni successivi dalla legge Gelli Bianco ribadisce la necessità che il giudice valuti l'ambito nel quale sono maturate le linee guida ed in particolare "le caratteristiche del soggetto od ella comunità che le ha prodotte, la sua veste istituzionale, il grado di indipendenza da interessi economici condizionanti”. Quando le linee guida appaiono frutto di una elaborazione scientifica condivisa ed affidabile possono costituire "la guida per un giudizio sulla colpa" che dispiega ampi riflessi anche "in tema di prova scientifica"

L’intervento della legge Gelli Bianco e la correlata codificazione delle fonti dalle quali possono essere tratte linee guida e protocolli, induce la giurisprudenza a rafforzare il ruolo riconosciuto a queste discipline, pur continuando a negarne il rango di regola cautelare di per sé integratrice del precetto colposo ${ }^{117}$.

La decisa negazione da parte della giurisprudenza dell'idoneità di linee guida e protocolli ad integrare, anche oggi, profili cautelari tipici della colpa specifica, non deve indurci in errore sul tenore che viene comunque riconosciuto a tali precetti. Essi infatti, se da un lato, sono considerati quali vere proprie regole cautelari la cui osservanza, nei parametri delineati dalla legge 24 del 2017, esclude la punibilità del fatto, dall'altro, addirittura determinano l'operatività di un meccanismo di successione della disciplina sulle responsabilità del sanitario fondata sulla successione delle norme integratrici del precetto ${ }^{118}$.

Risulta evidente come, soprattutto alla luce di quest'ultima considerazione, la giurisprudenza ritenga che il precetto delle linee guida (e dei protocolli) vada ad integrare l'art. 43 c.p. costituendo pertanto regola cautelare consustanziale al precetto colposo $^{119}$.

La circostanza appare confermata anche alla luce della recente giurisprudenza in tema di disastri naturali la quale, attraverso il paragone con i frattali, ha ritenuto che, anche nell'ambito oggetto della sua cognizione, talune "cautele procedurali" siano "sorvegliate” da regole tecniche.

\footnotetext{
${ }^{114}$ Cass. pen. sez. IV, 9 aprile 2013, n. 16237, Imp. Cantore, Rel. Baliotta, p. 8, in DeJure.

115 Cass. pen. sez. IV, 9 aprile 2013, n. 16237, cit., p. 14.

116 Cass. pen. sez. IV, 9 aprile 2013, n. 16237, cit., p. 15.

117 Cass. pen. sez. Un., 22 febbraio 2018, n. 8770, Rel. Vessichelli, in DeJure, p. 9 e nello stesso senso Cass. pen. sez. IV, 20 aprile 2017, Imp. De Luca, Rel. Blaiotta, in DeJure. In particolare, si afferma che "anche a seguito della procedura ora monitorata e governata nel suo divenire dall'apposita istituzione governativa, e quindi tendente a formare un sistema con connotati pubblicistici, le linee guida non perdono la loro intrinseca essenza, già messa in luce in passato con riferimento alle buone pratiche. Quella cioè di costituire un condensato delle acquisizioni scientifiche, tecnologiche e metodologiche concernenti i singoli ambiti operativi, reputate tali dopo un'accurata selezione e distillazione di diversi contributi, senza alcuna pretesa di immobilismo e senza idoneità ad assurgere a livello di regole vincolanti”.

118 Per tutti PADOVANI, T. (1982), Tipicità e successione di leggi penali. La modificazione legislativa degli elementi della fattispecie incriminatrice o della sua sfera di applicazione, nell' ambito dell'art. 2 commi 2 e 3 c.p., in Riv. it. dir. proc. pen., 1354.

${ }^{119}$ In questo senso anche MANTOVANI, F. (2017), Diritto penale, cit. p. 335.
} 
Ecco, ci dice la Corte, proprio la violazione di una di queste regole "è suscettibile di riverberarsi sulla cautela che tutte le contiene" e a questo punto "non si può qui dubitare della relazione con l'evento" ${ }^{120}$.

I giudici esortano a non creare cautele vuote ma a dare peso a regole dense di aspetti tecnici, che siano, per l'appunto, modali. Regole che indichino quel comportamento dotato di efficacia impeditiva o contenitiva dell'evento.

I preziosi approdi raggiunti dalla disciplina legislativa in tema di responsabilità del sanitario, e raccolti come stimolo esegetico dalla più attenta giurisprudenza, si estendono, a ben vedere, ai meccanismi di scelta del consulente tecnico e del perito.

La legge 24 del 2017 prevede infatti, all'art. 15, rubricato Nomina dei consulenti tecnici d'ufficio e dei periti nei giudizi di responsabilità sanitaria, che "Nei procedimenti civili e nei procedimenti penali aventi ad oggetto la responsabilità sanitaria, l'autorità giudiziaria affida l'espletamento della consulenza tecnica e della perizia a un medico specializzato in medicina legale e a uno o più specialisti nella disciplina che abbiano specifica e pratica conoscenza di quanto oggetto del procedimento, avendo cura che i soggetti da nominare, scelti tra gli iscritti negli albi di cui ai commi 2 e 3, non siano in posizione di conflitto di interessi nello specifico procedimento $\mathrm{o}$ in altri connessi e che i consulenti tecnici d'ufficio da nominare nell'ambito del procedimento di cui all'articolo 8, comma 1, siano in possesso di adeguate e comprovate competenze nell'ambito della conciliazione acquisite anche mediante specifici percorsi formativi" ${ }^{121}$.

Un simile paradigma è peraltro richiamato dal coevo Disegno di legge n. 2602 del 2017 recante il Testo Unico il quale reca la disciplina del Testo Unico della Normativa in materia di amianto la modifica degli artt. 221 e 225 del c.p.p. ${ }^{122}$

In particolare, se l'art. 120 DL 2602/2017, rubricato Modifica dell'articolo 221 del codice di procedura penale, prevede che: "All' articolo 221 del codice di procedura penale dopo il comma 1 è inserito il seguente: «1-bis. Nei procedimenti per i delitti di cui agli articoli 434, 437, 449, e 452-quater, primo comma, numero 3), del codice penale, in relazione ai quali il danno o il pericolo derivano dall'esposizione ad

\footnotetext{
${ }^{120}$ Cass. pen. Sez. IV, 24 marzo 2016, cit. p. 127 e 128.

${ }^{121}$ La norma completa la disciplina prevedendo inoltre che 2. Negli albi dei consulenti di cui al- l'articolo 13 delle disposizioni per l'attua- zione del codice di procedura civile e disposizioni transitorie, di cui al regio decreto 18 dicembre 1941, n. 1368, e dei periti di cui all'articolo 67 delle norme di attuazione, di coordinamento e transitorie del codice di procedura penale, di cui al decreto legislativo 28 luglio 1989, n. 271, devono essere indicate e documentate le specializzazioni degli iscritti esperti in medicina. In sede di revisione degli albi è indicata, relativamente a ciascuno degli esperti di cui al periodo precedente, l'esperienza professionale maturata, con particolare riferimento al numero e alla tipologia degli incarichi conferiti e di quelli revocati;

3. Gli albi dei consulenti di cui all'articolo 13 delle disposizioni per l'attuazione del codice di procedura civile e disposi- zioni transitorie, di cui al regio decreto 18 dicembre 1941, n. 1368, e gli albi dei periti di cui all'articolo 67 delle norme di attuazione, di coordinamento e transitorie del codice di procedura penale, di cui al decreto legislativo 28 luglio 1989, n. 271, devono essere aggiornati con cadenza almeno quinquennale, al fine di garantire, oltre a quella medico-legale, un'idonea e adeguata rappresentanza di esperti delle discipline specialistiche riferite a tutte le professioni sanitarie, tra i quali scegliere per la nomina tenendo conto della disciplina interessata nel procedimento;

4. Nei casi di cui al comma 1, l'incarico è conferito al collegio e, nella determinazione del compenso globale, non si applica l'aumento del 40 per cento per ciascuno degli altri componenti del collegio previsto dall'articolo 53 del testo unico delle disposizioni legislative e regolamentari in materia di spese di giustizia, di cui al decreto del Presidente della Repubblica 30 maggio 2002, n. 115.

122 Disegno di legge n. 2602 del 2017, reperibile su www.senato.it.
} 
amianto, non- ché nei procedimenti per i delitti di cui agli articoli 452-ter, 575, 582, 589, secondo e quarto comma, 590, terzo e quarto comma, del codice penale, per malattie asbesto derivate, il giudice a pena di nullità sceglie il perito fra i professionisti di comprovata esperienza nell'ambito tecnico-scientifico sul quale verte la perizia. Nella scelta, il giudice si serve dell'apposito albo istituito presso l'Agenzia nazionale amianto», l'art. 121 Rubricato Modifica dell'articolo 225 del codice di procedura penale, dispone che all'articolo 225 del codice di procedura penale, dopo il comma 1, è inserito il seguente: «1-bis. Nei procedimenti per i delitti di cui agli articoli 434, 437, 449, e 452-quater, primo comma, numero 3), del codice penale, in relazione ai quali il danno o il pericolo derivano dall'esposizione ad amianto, nonché nei procedimenti per i delitti di cui agli articoli 452-ter, 575, 582, 589, secondo e quarto comma, 590, terzo e quarto comma, del codice penale, per malattie asbesto derivate, il pubblico ministero a pena di nullità sceglie il consulente tecnico fra i professionisti di comprovata esperienza nell'ambito tecnico-scientifico sul quale verte la consulenza. Nella scelta, il pubblico ministero si serve dell'apposito albo istituito presso l'Agenzia nazionale amianto».

In realtà, occorrerebbe cessare rapidamente dall'assecondare la tentazione di codificazioni settoriali volte a creare statuti peculiari in ordine ad alcune discipline e tornare piuttosto a concepire il diritto penale (e di riflesso il suo precipitato processuale) quale strumento attuativo di un sistema di valori condivisi da trasfondere nell'ordinamento nel suo complesso.

La previsione autonoma di uno statuto della colpa medica cui si correla un peculiare e più garantista sistema probatorio, affidato alle più sapienti mani di periti e consulenti tecnici scelti ai sensi dell'art. 15 nulla può se l'ordinamento non si apre ad una valutazione sistemica e condivisa del rischio quale unico antidoto possibile alle risposte disfunzionali offerte da una giurisprudenza moralizzatrice ormai decontestualizzata dal suo ruolo costituzionale ${ }^{123}$.

Se dunque il recupero del rimprovero colposo alla sua dimensione scientifica presuppone non solo un peculiare processo di codificazione, scelta ed elezione delle regole cautelari ad opera di organismi particolarmente autorevoli, ma anche la veicolazione del sapere esperto nel processo penale ad opera di soggetti particolarmente qualificati, è pur vero che, come abbiamo visto, il deficit regolamentare e normativo che accompagna e presidia questo processo risulta ancora assai fragile e inefficace quando sia calato su ambiti del rischio diversi da quello medico ${ }^{124}$.

L'irreale attesa di una nuova e più proficua codificazione volta a presidiare, anche con strumenti penalistici, il corretto svolgimento delle funzioni di perito e consulente tecnico nel processo penale può essere in parte confortata dalla valorizzazione di strumenti solo apparentemente meno cogenti quali quelli imposti dalla deontologia professionale ai diversi attori del processo penale.

Le riflessioni maturate in seno ad una recente iniziativa promossa dal Dipartimento di Scienze Giuridiche dell'Università di Firenze ed intitolata "Il Penalista tra deontologia e prassi” hanno evidenziato la necessità del recupero della dimensione del difensore, del pubblico ministero, del giudice, del consulente tecnico e del perito

123 Del resto, anche la più autorevole Dottrina sottolinea come il novero delle attività rischiose ma autorizzate costituisca una unità concettuale per la quale possono valere comuni regole di disciplina ed esegetiche (nel rispetto delle reciproche differenze. In questo senso, MANTOVANI, F. (2017), Diritto penale, cit. p. 344 parla a proposito di “colpa speciale”.

${ }^{124} \mathrm{Ne}$ è certamente riprova l'assunto della Suprema Corte poco sopra citato. Cass. pen. Sez. IV, 24 marzo 2016, cit. p. 127 e 128. 
alla dimensione deontologica. Con particolare riferimento alla figura di periti e consulenti tecnici si è sottolineata la necessità riflettere in ordine alle conseguenze, non oggetto di specifiche disposizioni normative, che scaturiscono dall'"investitura fiduciaria” legata alla scelta costante, soprattutto da parte del pubblico ministero, di un certo professionista che gli assicuri l'apporto nel processo di risultanze scientifiche funzionali alla scelta accusatoria. Si è giustamente rivolto l'invito non soltanto a considerare la mancanza di una disciplina positiva in ordine alle ipotesi nella quale il professionista ponga la propria competenza ora a servizio del giudice, ora della pubblica accusa, ora della parte privata, ma altresì ad interrogarsi sulla credibilità di questo “esperto $<$ polivalente $>$ " 125 .

Tutti questi aspetti portano a riflettere, inoltre, sulla necessità di non demandare alla codificazione la regolamentazione di prassi virtuose quali strumenti idonei a consentire un proficuo incontro fra scienza e diritto nel procedimento e nel processo penale.

Le non infrequenti ipotesi nelle quali il giudice possa essere fuorviato da contenuti scientifici portati nel processo da soggetti inidonei al ruolo al quale sono stati chiamati, potrebbe essere scongiurata dalla creazione di prassi virtuose, maturate anche a livello delle singole sedi di Corte d'Appello, che abbiano ad oggetto: a. la valutazione, in sede di conferimento dell'incarico, nel contraddittorio orale fra le parti, delle competenze del tecnico o dello scienziato chiamato ad offrire il suo apporto conoscitivo nel processo penale; b. la creazione di una "griglia logica" articolata per punti, strutturata come una timeline o una check list, attraverso la quale il giudice possa ripercorrere la correttezza dell'iter logico - scientifico seguito dal perito o dal consulente tecnico, verificandone in tal modo quella correttezza formale che, in molti casi, coincide con la validità sostanziale dell'apporto scientifico ${ }^{126}$.

Se il combinato disposto di scelte legislative maggiormente lungimiranti e di prassi virtuose potrà indicare la strada della buona scienza ad un giudice oggi privo di concreti riferimenti, pur tuttavia solo l'etica e il buon senso ci salveranno dai più biechi rigurgiti di un malinteso neopositivismo che si invera nei pericolosi strumenti predittivi che la modernità intenderebbe offrire ai propri adepti.

\section{BIBLIOGRAFIA}

ACCINNI, G. P. (2006), Criteri di imputazione per colpa tra leggi scientifiche e accertamenti giudiziali, in Riv. it. dir. proc. pen., p. 930.

ALESSANDRI, A. (1983), Reati d'impresa e modelli sanzionatori, Milano.

AMATO, A. - FLORA, G. - VALBONESI, C. (2019), Scienza, diritto e processo penale nell'era del rischio, Torino.

AMATO, A. - GALADINI, F. (2013), Gli argomenti della scienza nel processo dell'Aquila alla "Commissione Grandi Rischi", in Rivista di cultura e politica scientifica, p. 7 ss.

AMATO, A. - CERASE, A. - GALADINI, F. (2015), Terremoti, comunicazione, diritto. Riflessioni sul processo alla "Commissione Grandi Rischi", Roma.

125 PAONESSA, C. (2019), Deontologia e prassi del consulente tecnico e del perito: spunti per un dibattito, in www.disCrimen.it, 19 marzo 2019, [consultato il 13 giugno 2019].

${ }^{126}$ Dall'intervento del Giudice CASSANO, M., Presidente della Corte d'Appello di Firenze, al Corso di perfezionamento in diritto e procedura penale, dal titolo "Il Penalista tra deontologia e prassi" svoltosi presso il Dipartimento di Scienze Giuridiche dell’Università di Firenze il giorno 15 marzo 2019. 
AMATO, G. (2017), Professionisti "salvi" se l'evento dannoso è dovuto a imperizia, in Guida dir., n. 15, p. 51; BRUSCO, C. (2017), La nuova legge sulla responsabilità professionale degli esercenti le professioni sanitarie, in www.ilpenalista.it, 1 marzo 2017.

ARROYO ALFONSO, M. S. (2018), Apuntes sobre la administrativización del derecho penal del medio ambiente, in Actualidad Jurídica Ambiental, n. 83, Sección “Artículos doctrinales”, 1ottobre 2018.

BARTOLI, R. (2018), Diritto penale e prova scientifica, in CANZIO G.-LUPARIA L. (a cura di), Prova scientifica e processo penale, Milano, p. 80.

BARTOLOMMEI, S. (2001), Sul principio di precauzione: norma assoluta o regola procedurale?, in Bioetica, , p. 321; BECK, U. (2000), La società del rischio. Verso una seconda modernità, Roma.

BELL, A. H. -VALSECCHI, A. (2015), Il nuovo delitto di disastro ambientale: una norma che difficilmente avrebbe potuto essere scritta peggio, www.penalecontemporaneo.it, [consultato il 13 giugno 2019]; RUGA RIVA, C. (2015), Dolo e colpa nei reati ambientali, in www.penalecontemporaneo.it, 19 gennaio 2015, [consultato il 13 giugno 2019], p. 2 e ss.

BERNASCONI, A. (2008), (voce) Responsabilità amministrativa degli enti (profili sostanziali e processuali), in Enc. Dir. Annali, Milano, p. 961

BLAIOTTA, R. (1997), Il realismo di Karl Popper: un ideale di conoscenza oggettiva per il giudizio penale, in Cass. pen., p. 3689.

BRICOLA, F. (1970), Il costo del principio "societas delinquere non potest" nell'attuale dimensione del fenomeno societario, in Riv. it. dir. proc. pen., p. 951 ss.

BRICOLA, F., Teoria generale del reato, in Nov.mo dig. it., vol. XIX, Torino, 1973, p. 7.

BRUSCO, C. (2012), Rischio e pericolo, rischio consentito e principio di precauzione. La c.d. «flessibilizzazione delle categorie del reato», in Criminalia, p. 383.

BRUSCO, C. (2010), Brevi considerazioni sulla prevedibilità dell'evento nel reato colposo, in BARTOLI, R. (a cura di), Responsabilità penale e rischio nelle attività mediche e d'impresa, Firenze, p. 493.

BRUSCO, C. (2017), Cassazione e responsabilità del medico. Tipicità e determinatezza del nuovo art. 590 sexies c.p., in Dir. pen. cont., p. 211.

BRUSCO, C. (2017), La colpa penale e civile, Milano, spec. p. 233.

CAIANIELLO, M. (2013), Imputazione e garanzie: la contestazione e la qualificazione del fatto nel reato colposo, in DONINI, M. - ORLANDI, R. (a cura di), Reato colposo e modelli di responsabilità, Bologna, p. 241.

CAPUTO, M. (2017), La responsabilità penale dell'esercente la professione sanitaria dopo la L. n. 24 del 2017 ... "quo vadit”? Primi dubbi, prime risposte, secondi dubbi, in Danno e responsabilità, p. 293.

CAPUTO, M. (2017), I nuovi limiti della sanzione penale, in LOVO, M. - NOCCO L. (a cura di), La nuova responsabilità sanitaria. Le novità introdotte dalla Legge Gelli, Milano, p. 26; ID, Colpa penale del medico e sicurezza delle cure, Torino, 2017.

CARNELUTTI, F. (1946), Saggio di una teoria integrale dell'azione, in Riv. dir. proc. civ., p. 17. 
CASTRONUOVO, D. (2002), La contestazione del fatto colposo: discrasie tra formule prasseologiche d'imputazione e concezioni teoriche della colpa, in Cass. pen., p. 3836;

CASTONUOVO, D. (2012), Principio di precauzione e diritto penale, Roma;

CECCHI, M. (2017), L'”autonoma valutazione" del giudice quale baluardo contro l'appiattimento sulla prova scientifica, in Dir. pen. proc., p. 915.

CENTONZE, A. (2001), Scienza «spazzatura» e scienza «corrotta» nelle attestazioni e valutazioni dei consulenti tecnici nel processo penale, in Riv. it. dir. proc. pen., p. 1232;

CENTONZE, A. (2004), La normalità dei disastri tecnologici. Il problema del congedo dal diritto penale, Milano, p. 178;

CENTONZE, F. -CAPUTO, M. (2016), La risposta penale alla malpractice: il dedalo di interpretazioni disegnato dalla riforma Gelli-Bianco, in Riv. it. med. leg., p. 1361.

CERASE, A. (2017), Rischio e comunicazione. Teorie, modelli, problemi, Torino.

CONSORTE, F. (2007), Spunti e riflessioni sul principio di precauzione e sugli obblighi di tutela penale, in Dir. Pen. XXI secolo, p. 271.

CONSORTE, F. (2011), Principio di precauzione e beni legati alla sicurezza. La logica precauzionale come fattore espansivo del penale nella giurisprudenza della Cassazione, in www.penalecontemporaneo.it, oggi confluito in GRASSO, G. PICOTTI, M.- SICURELLA, R. (a cura di), L'evoluzione del diritto penale nei settori d'interesse europeo alla luce del Trattato di Lisbona, Milano, 2011;

CONTI, C. (2009), Evoluzione della scienza e ruolo degli esperti nel processo penale, in S. CANESTRARI, S.- GIUNTA F. - GUERRINI, R. - PADOVANI, T. (a cura di), Medicina e diritto penale, Pisa, p. 336;

CONTI, C. (2011), (a cura di), Scienza e processo penale. Nuove frontiere e vecchi pregiudizi, Milano.

CORDERO, F. (1958), Considerazioni sul principio di identità del "fatto", in Riv. it. dir. proc. pen., p. 940.

D’AVIRRO, A. - DI AMATO, A. (2009), La responsabilità da reato degli enti, Padova.

DALFINO, D. (2018), Creatività e creazionismo, prevedibilità e predittività, in Foro It., V, p. 385.

DE FRANCESCO, G. (2012), L'imputazione della responsabilità penale in campo medico-chirurgico: un breve sguardo d'insieme, in Riv. it. med. Leg., p. 970.

DE FRANCESCO, G. (2017), In tema di dovere terapeutico, colpa medica e recenti riforme, in www.lalegislazionepenale.eu, 2 maggio 2017.

DE LEONARDIS, F. (2007), Il principio di precauzione nell'amministrazione di rischio, Milano, p. 48.

DE LIA, A. (2017), La "colpa medica”: dal tramonto del modello "Balduzzi” all'alba di un nuovo sistema. Brevi note su di una riforma in stile "pulp", in www.archiviopenale.it, 27 giugno 2017.

DE SIMONE, G. (2012), Persone giuridiche e responsabilità da reato. Profili storici, dogmatici e comparatistici, Pisa

DE VERO, G. (2008), La responsabilità penale delle persone giuridiche, Milano.

DEVOTO, G. - OLI, G. C. (2019), Voce "Prudenza (virtù teologale)", Dizionario della lingua italiana, Firenze. 
DI SALVO, E. (2009), Esposizione a sostanze nocive, leggi scientifiche e rapporto causale nella pronuncia della Cassazione sul caso Porto Marghera (nota a Cass. sez. IV, 6 febbraio 2007, 4675, imp. Bartalini), in Cass. pen., p. 2877. MICHELETTI, D. (1996), Tumori da amianto e responsabilità penale, in Riv. trim. dir. pen. econ., p. 231.

DI SALVO, E. (2009), Esposizione a sostanze nocive, leggi scientifiche e rapporto causale nella pronuncia della Cassazione sul caso 'Porto Marghera' [Nota a sentenza] sez. IV, 17 maggio 2006, n. 4675, imp. Bartalini, cit., p. 2788.

DOMINIONI O. (2005), La prova penale scientifica. Gli strumenti scientifico-tecnici nuovi o controversi e di elevata specializzazione, Milano, passim.

DOMINIONI, O. (2012), In tema di nuova prova scientifica, in Dir. pen. proc., p. 1064.

DONDERO, B. (2017), La Justice predictive, in https: //brunodondero.com/2017/02/01/lajusticepredictive, 2017, DONINI, M. (2011), Europeismo giudiziario e scienza penale, Milano, p. 132 ss.

EUSEBI, L. (2000), Appunti sul confine fra dolo e colpa nella teoria del reato, in Riv. it. dir. proc. pen., p. 1064.

EWALD, F. (2001), Philosophie politique du principe de précaution, Gollier, p. 21.

FALZEA, A. (1981), La responsabilità penale della persona giuridica, in AA.VV. La responsabilità penale delle persone giuridiche in diritto comunitario, p. 149.

FERRARA, F. (2014), La responsabilità delle persone giuridiche, in Riv. dir. com., p. 513.

FODDAI, M. A. (2017), Controversie scientifiche e controversie giuridiche: $i$ limiti della decisone giudiziale, in Politeia, p. 60.

FORNARI, L. (1999), Descrizione dell'evento e prevedibilità del decorso causale: «passi avanti» della giurisprudenza sul terreno dell'imputazione col- posa, in Riv. it. dir. proc. pen., p. 725.

FORTI, G. (2006), Accesso alle informazioni sul rischio e responsabilità: una lettura del principio di precauzione, in Criminalia, p. 155.

FORTI, G. (2007), La chiara luce della verità e l'ignoranza del pericolo. Riflessioni penalistiche sul principio di precauzione, in AA. VV. (a cura di) Scritti per Federico Stella, Napoli, p. 573.

GALLINO, L. (2012), L'incerta alleanza: modelli di relazione fra scienze umane $e$ scienze della natura, Torino, passim.

GARGANI, A. (2006), Individuale e collettivo nella responsabilità della societas, in St. sen., p. 273.

GARGANI, A. (2011), Dal diritto penale dell'evento al diritto penale del rischio: problemi e prospettive, relazione al convegno del CSM Il diritto penale del rischio, Roma 2-4 maggio 2011, p. 2.

GIUNTA, F. (1993), Illiceità e colpevolezza nella responsabilità colposa, Padova, pp. 14, 133, 141, 150, 155;

GIUNTA, F. (1999), I tormentati rapporti fra colpa e regola cautelare, in Dir. pen. proc., 1295;

GIUNTA, F. (1999), La normatività della colpa penale. Lineamenti di una teorica, in Riv. it. dir. proc. pen., p. 95. GIUNTA, F. (2002), Principio e dogmatica della colpevolezza nel diritto penale d'oggi, in Riv. it. dir. proc. pen., p. 123.

GIUNTA, F. (2006), Il diritto penale e le suggestioni del principio di precauzione, in Criminalia, p. 227; 
GIUNTA, F. (2008), Il diritto penale e le suggestioni del principio di precauzione, cit. p. 241.

GIUNTA, F. (2008), La legalità della colpa, in Criminalia, p.151.

GIUNTA, F. (2008), voce Principio di precauzione, in ID (a cura di), Dizionario di Diritto penale, Milano, Il Sole 24 Ore, p. 905 ss.,

GIUNTA, F. (2013), Protocolli medici e colpa penale secondo il "Decreto Balduzzi”, in Riv. it. med. leg., p. 819;

GIUNTA, F. (2015), Questioni scientifiche e prova scientifica tra categorie sostanziali e regole di giudizio, in BERTOLINO, M.-UBERTIS, G. (a cura di), Prova scientifica, ragionamento probatorio e decisione giudiziale, Napoli, p. 57.

GIUNTA, F. (2016), Maxima culpa, in Giust. Pen., p. 635.

GIUNTA, F. (2019), Culpa culpae, cit. apparso su www.disCrimen.it dal 4 giugno 2019

GROTTO, M. (2012), Principio di colpevolezza, rimproverabilità soggettiva e colpa specifica, Torino, passim. CASTRONUOVO, D. (2009), La colpa penale, Milano, p. 182.

GROTTO, M. (2015), Obbligo di informazione e formazione dei lavoratori, nesso di rischio e causalità della colpa, in www.penalecontemporaneo.it, 16 settembre 2015 [consultato il 13 giugno 2019].

GUERRINI, R. (2006), La responsabilità da reato degli enti, Milano;

IRTI, N. (2014), La crisi della fattispecie, in Riv. dir. proc., p. 43.

IRTI, N. (2016), Un diritto incalcolabile, Torino, p. 14.

IRTI, N., (2014), Calcolabilità weberiana e crisi della fattispecie, in Riv. dir. civ., p. p. 987.

ISOLABELLA, L.- QUADRARO, A. (2017), Così l'osservanza delle pratiche cliniche diventa tassativa, in Guida dir., n. 15, p. 56 e ss..

JASANOFF, S. (2001), La scienza davanti ai giudici, Milano.

JONAS, H. (1979), Das Prinzip Verantwortung, Frankfurt am Main, tr. It. Il principio della responsabilità. Un' etica per la civiltà tecnologica. Torino, 1993, passim.

LANCELLOTTI, G. (2003), La responsabilità delle società per il reato dell'amministratore, Torino.

LATTANZI, G. (2010), Reati e responsabilità degli enti, Milano.

LIPARI, N. (2015), Il diritto quale crocevia fra le culture, in Riv. trim. dir. proc. civ., 2015, p. 1.

LOEVINGER, L. (1949), Jurimetrics: The Next Step Forward, in Minnesota Law Review.

MANTOVANI, F. (2007), Umanità e razionalità del diritto penale, Padova.

MANTOVANI, F. (2017), Diritto penale. Parte generale., Padova, p. 333. Sulla prevedibilità dell'evento nella letteratura penalistica, ex plurimis.

MARINI, G. (1994), «Rischio consentito» e tipicità della condotta. Riflessioni, in Scritti in memoria di Renato Dell'Andro, Bari, p. 560.

MARINI, G. (2004), Principio di precauzione, sicurezza alimentare e organismi geneticamente modificati nel diritto comunitario, Il Diritto dell'Unione Europea, p. 281.

MARINUCCI, G. (2012), Il ruolo delle regole scritte di diligenza nell'era dello sviluppo tecnico, Relazione presentata al Convegno "La criminalità colposa: aspetti giuridici e medico sociali" Camerino, 24-24 ottobre 1971, pubblicata nella sua originaria versione, in I quaderni degli incontri, 114, 1972, p. 5 e 79 e oggi pubblicata nel volume La Colpa, Studi, Milano, p. 295. 
MARINUCCI, G. (2002), "Societas puniri potest” uno sguardo sui fenomeni e sulle discipline contemporanee, in Riv. it. dir. proc. pen., p. 1193.

MARINUCCI, G., Brevi note sul caso fortuito come scusante del fatto colposo, Nota a Trib. Firenze, Sez. I, 18.6.2012 (dep. 15.11.2012), Giud. Boncompagni, in www.penalecontempornaeo.it, 13 maggio 2013.

MASSARO, A. (2009), «Concretizzazione del rischio» e prevedibilità dell'evento nella prospettiva della doppia funzione della colpa, in Cass. pen., p. 4699.

MICHELETTI, D. (2000), La colpa nella bancarotta semplice patrimoniale, in Riv. tim. dir. pen. econ., p. 628;

MICHELETTI, D. (2000), La colpa nella bancarotta semplice patrimoniale. Contributo allo studio del la regola cautelare come criterio di delimitazione della tipicità colposa, in Riv. trim. dir. pen. econ., p. 609.

MICHELETTI, D. (2008), La colpa del medico, Prima lettura di una recente ricerca sul campo, in Criminalia, p. 174.

MICHELETTI, D. (2009), La normatività della colpa medica nella giurisprudenza della Cassazione, in Medicina e diritto

penale, in CANESTRARI, S. -GIUNTA, F.- GUERRINI, R.- PADOVANI, T. (a cura di), Pisa, p. 266.

MILITELLO, V. (1988), Rischi e responsabilità penale, Milano, p. 152.

MORELLI, C. (2017), Giustizia predittiva: in Francia è online la prima piattaforma europea. Uno strumento per garantire la certezza del diritto?, in www.altalex.it, 3 aprile 2017.

MORGANTE, G. (2010), Spunti di riflessione sul diritto penale e sicurezza del lavoro nelle recenti riforme legislative, in Cass. pen., p. 3319.

MUCCIARELLI, F. (2000), Colpa e causalità: una sentenza contro il brocardo «qui in re illicita versatur, tenetur etiam pro casu», in Foro Ambrosiano.

MUSCO, E. (1971), La contestazione dei reati colposi, in Riv. it. dir. proc. pen., p. 330.

ORESTANO, R. (1978), "Persona” e "persone giuridiche” nell'età moderna, in Azioni, Diritti soggettivi, persone giuridiche, p. 209.

PADOVANI, T. (1982), Tipicità e successione di leggi penali. La modificazione legislativa degli elementi della fattispecie incriminatrice o della sua sfera di applicazione, nell' ambito dell'art. 2 commi 2 e 3 c.p., in Riv. it. dir. proc. pen., 1354.

PADOVANI, T. (2004), Il nome dei principi e il principio dei nomi: la responsabilità "amministrativa” delle persone giuridiche, in DE FRANCESCO, G. (a cura di), La responsabilità degli enti: un nuovo modello di giustizia punitiva, Torino.

PALAZZO, F. (2003), Societas puniri potest, La responsabilità da reato degli enti collettivi, Padova.

PALIERO, C.E. (2001), Il d.lgs. 8 giugno 2011, n. 231: da ora in poi societas delinquere (et puniri) potest, in Corr. giur., p. 845.

PALMA, M. (2017), Molto rumore per nulla: la legge Gelli-Bianco di riforma della responsabilità penale del medico, in Riv. it. med. leg., p. 523;

PAONESSA, C. (2019), Deontologia e prassi del consulente tecnico e del perito: spunti per un dibattito, in www.disCrimen.it, 19 marzo 2019.

PERIN, A. (2012), Colpa penale relazionale e sicurezza nei luoghi di lavoro, in Dir. pen. cont., p. 10.

PERINI C. (2011), Il concetto di rischio nel diritto penale moderno, Milano, p. 519. 
PERINI, C. (2011), Dal diritto penale dell'evento al diritto penale del rischio: problemi e prospettive, Parte II, relazione al convegno del CSM Il diritto penale del rischio, Roma 2-4 maggio 2011, p. 1;

PIERGALLINI, C. (2005), Il paradigma della colpa nell'età del rischio: prove di resistenza del tipo, in Riv. it. dir. proc. pen., p. 1692

PIERGALlinI, C. (2005), Paradigma della colpa nell'età del rischio: prove di resistenza del tipo, in Riv. it. dir. pen. econ., p. 1697.

PIERGALLINI, C. (2005), Paradigma della colpa nell'età del rischio: prove di resistenza del tipo, in Riv. it. dir. pen. econ., p. 1697;

PIERGALLINI, C. (2005), Paradigma della colpa nell'età del rischio: prove di resistenza del tipo, cit., p. 1699.

PIERGALLINI, C. (2006), Esposizione ad amianto e tutela della salute: profili penalistici, in MONTUSCHI, L. - INSOLERA, G. (a cura di), Il rischio da amianto, Bologna, p. 31; INSOLERA, G., (1997), Attività produttive e imputazione per colpa: prove tecniche di «diritto penale del rischio» in Riv. it. dir. proc. pen., p. 1473.

PIERGALLINI, C. (2007), La regola dell'oltre ogni ragionevole dubbio al banco di prova di un ordinamento di civil law, in Riv. it. dir. proc. pen., p. 599

PIOLETTI, U. (1990), Contributo allo studio del delitto colposo, Padova.

PONGILUPPI, A. (2010), Principio di precauzione e reati alimentari, in Riv. trim. dir. pen. econ., p. 260.

PULITANÒ, D. (2006), Gestione del rischio da esposizioni professionali, in Cass. pen., p. 778.

PULITANÒ, D. (2006), Il diritto penale fra vincoli di realtà e sapere scientifico, in Riv. it. dir. proc. pen., p. 795.

PULITANÒ, D. (2006), Il diritto penale fra vincoli di realtà e sapere scientifico, in Riv. it. dir. proc. pen., p. 795.

PULITANÒ, D. (2008), Colpa ed evoluzione del sapere scientifico, in Dir. pen. proc., p. 649.

RISICATO, L. (2017), Il nuovo statuto penale della colpa medica: un discutibile progresso nella valutazione della responsabilità del personale sanitario, in www.lalegislazionepenale.eu, 5 giugno 2017.

RUGA RIVA, C. (2006), Principio di precauzione e diritto penale. Genesi e contenuto della colpa in contesti di in- certezza scientifica, in Studi in onore di Giorgio Marinucci, Milano, p. 1743.

ROMANO, M. (1995), Societas delinquere non potest (nel ricordo di Franco Bricola), in Riv. it. dir. proc. pen., p. 1037.

ROMANO, M. (2002), La responsabilità amministrativa degli enti, società o associazioni. Profili generali, in Riv. Soc., p. 303.

SANTI, F. (2004), La responsabilità delle società e degli enti, Milano.

SCOLETTA, M. M. (2014), La responsabilità da reato delle società: principi generali e criteri imputativi del d.lgs. 231/2001 in CERQUA, L. D. -CANZIO, G.LUPARIA, L. (a cura di), Diritto penale delle società, Padova, p. 46.

SCORDAMAGLIA, I. (2012), Il diritto penale della sicurezza del lavoro tra i principi di prevenzione e di precauzione, in www. penalecontemporaneo.it, 23 novembre 2012.

SGUBBI, F. (2001), Il diritto penale incerto ed efficace, in Riv. it. dir. pen. econ., p. 1197. 
SNOW, C. P. (1959), The Two Cultures and a Second Look, Cambridge University Press.

STELLA F. (1999), Scienza e norma della pratica dell'igiene industriale, in Riv. it. dir. proc. pen. p. 382;

STELLA, F. (2002), Giustizia e modernità, La protezione dell'innocente e la tutela delle vittime, cit., passim.

STELLA, F. (2002), Verità, scienza e giustizia: le frequenze medio - basse nella successione di eventi, in Riv. it. dir. proc. pen., p. 1218

STELLA, F. (2003), Giustizia e modernità. La protezione dell'innocente e la tutela delle vittime, Milano, p. 156;

STELLA, F., (2003), La costruzione giuridica della scienza: sicurezza e salute negli ambienti di lavoro, in Riv. it. dir. proc. pen., p. 55.

STORTONI, L. (2004), Angoscia tecnologica ed esorcismo penale, in Riv. it. dir. proc. pen., p. 70.

TARUFFO, M. (2005), Conoscenza scientifica e decisone giudiziaria: profili generali, in AA. VV., Decisione giudiziaria a verità scientifica, Milano, p. 6.

TONINI, P. (2003), Prova scientifica e contraddittorio, in Riv. it. dir. proc. pen., p. 1459 ss..

TONINI, P. (2008), La prova scientifica: considerazioni introduttive, in Dir. pen. proc., n.6, Dossier La prova scientifica nel processo penale, p. 7 ss..

TONINI, P. (2015), Nullum iudicium sine scientia. Cadono vecchi idoli nel caso Meredith Kercher, in Dir. pen. proc., p. 1411.

TORRE, V. (2016), Linee guida e tassatività, in AA.VV. (a cura di) Scritti in onore di Luigi Stortoni, Bologna, p. 309 TERROSI VAGNOLI, E. (1999), Le linee guida per la pratica clinica: valenze e problemi medico legali, in Riv. it. med. leg., p. 189.

VALBONESI, C. (2016), Terremoti colposi e terremoto della colpa. riflessioni a margine della sentenza "grandi rischi”, in Riv. it. dir. proc. pen., 2016, p. 1496.

VARRASO, G. (1999), Omessa o insufficiente descrizione dell'imputazione, nullità della vocatio in iudicium e autorità competente alla rinnovazione, in Riv. it. dir. proc. pen., p. 339.

VENEZIANI, P. (2013), Causalità della colpa e comportamento alternativo lecito, in DONINI, M. -ORLANDI, R. (a cura di), Reato colposo e modelli di responsabilità, Bologna, p. 298.

VERRICO, A. (2011), La prevedibilità e l'evitabilità dell'evento nel caso di calamità naturali, in Cass. pen., p. 110;

VIGANÒ, F. (2016), Il principio di prevedibilità della decisione giudiziale in materia penale, in PALIERO, C.E. - MOCCIA, S.- DE FRANCESCO, G. A. INSOLERA, G. - PELISSERO, M.- RAMPIONI, R.- RISICATO, L. (a cura di), La crisi della legalità. Il "sistema vivente delle fonti penali", ESI, Napoli.

VIOLA, L., Giustizia predittiva, in www.treccani.it, 2018.

WILLIAMS, B. (2005), Genealogia della verità, Roma.

ZIRULIA, S. (2011), Amianto e responsabilità penale: causalità ed evitabilità dell'evento in relazione alle morti derivate da mesotelioma pleurico, in www.penalecontemporaneo.it, 11 gennaio, 2011 [consultato il 13 giugno 2019]; ID., Amianto, la prova dell'innocenza non è evidente: tutti prosciolti per prescrizione nel giudizio di rinvio dopo la sentenza Cozzini, in www.penalecontemporaneo.it, 13 settembre 2012. 